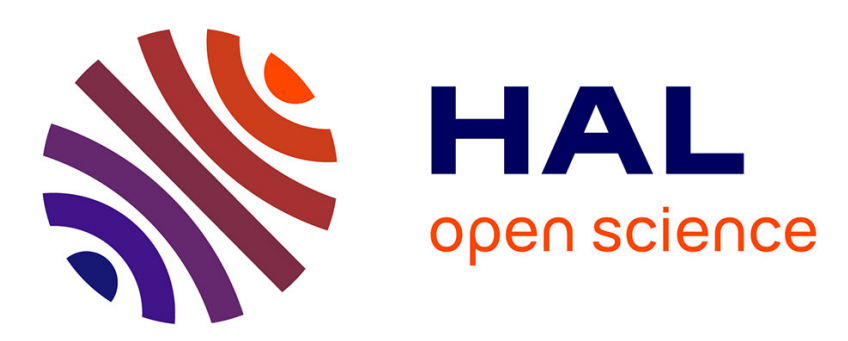

\title{
A surface runoff mapping method for optimizing risk assessment on railways
}

L.R. Lagadec, L. Moulin, Isabelle Braud, B. Chazelle, Pascal Breil

\section{To cite this version:}

L.R. Lagadec, L. Moulin, Isabelle Braud, B. Chazelle, Pascal Breil. A surface runoff mapping method for optimizing risk assessment on railways. Safety Science, 2018, 110 (part B), pp.253-267. 10.1016/j.ssci.2018.05.014 . hal-02607962

\section{HAL Id: hal-02607962 \\ https://hal.inrae.fr/hal-02607962}

Submitted on 16 May 2020

HAL is a multi-disciplinary open access archive for the deposit and dissemination of scientific research documents, whether they are published or not. The documents may come from teaching and research institutions in France or abroad, or from public or private research centers.
L'archive ouverte pluridisciplinaire HAL, est destinée au dépôt et à la diffusion de documents scientifiques de niveau recherche, publiés ou non, émanant des établissements d'enseignement et de recherche français ou étrangers, des laboratoires publics ou privés. 
Author-produced version of the article published in Safety science, 2018; 110 part B : 253-267

Title: A surface runoff mapping method for optimizing risk assessment on railways

Lilly-Rose Lagadec ${ }^{1,2,3}$, Loïc Moulin ${ }^{1}$, Isabelle Braud ${ }^{2}$, Blandine Chazelle ${ }^{4}$, Pascal Breil ${ }^{2}$

1 SNCF Réseau (French Railway Company), Engineering \& Projects Direction, Railways, Tracks \& Environment Department, 6 avenue Francois Mitterrand, 93210 La-Plaine-Saint-Denis, France. cédex, France.

3 SNCF Réseau (French Railway Company), Engineering and Projects South-West, PIEG General Studies, 54 bis rue Amédée Saint Germain, 33077 Bordeaux, France.

4 SNCF Réseau (French Railway Company), Engineering and Projects South-East, General Studies, 31 Avenue Albert-et-Elisabeth, 63037 Clermont-Ferrand Cedex, France.

Corresponding author: Irlagadec@gmail.com

Abstract:

Railways are critical infrastructures for the transportation of people and goods and network failures must be controlled in order to maintain safety and to limit economic losses. The railway network is exposed to natural hazards and particularly to intense pluvial runoff. Due to the complexity of the phenomenon, management of risks induced by pluvial runoff raises technical and scientific issues. An innovative method for runoff susceptibility mapping, called IRIP for "Indicator of Intense Pluvial Runoff", has been created and adapted to the railway context. The objective of this paper is to evaluate the relevance of the mapping method and to provide application advice. The mapping method is evaluated by comparison with the results of a hydraulic diagnosis, on a $20 \mathrm{~km}$ railway line, using quantitative and qualitative comparisons. On the basis of contingency tables, probabilities of detection (POD, railway sections exposed and detected by IRIP) and false alarm ratios (FAR, railway sections detected by IRIP whereas they are not exposed) are computed. POD range from 94 to 100\% and FAR range from 20 to $26 \%$. Then spatial information provided by the maps is compared with field observations and recommendations. It is shown that the mapping method can bring substantial contribution to risk identification and that the IRIP method can allow pushing forward the current risk reduction methods. Thus, the surface runoff maps open up new opportunities to manage surface runoff, such as targeting mitigation actions at the origin of the hazard in partnership with the other territory stakeholders. 
31 Highlights:

32

33

34

35

36

37

- The IRIP method "Indicator of Intense Pluvial Runoff" maps the surface runoff susceptibility.

- The method performance and reliability are evaluated in the railway context

- The IRIP method makes a substantial contribution to risk assessment

- Surface runoff maps open up new opportunities to push forward the current processes

Keywords: Railway infrastructure; natural hazards; water surface runoff; risk assessment;

mapping method; evaluation 
Author-produced version of the article published in Safety science, 2018; 110 part B : 253-267

1. Introduction

1.1. Context

Railways are critical infrastructures for the transportation of people and goods (Maurer et al., 2012). The French railway network operates about $30,000 \mathrm{~km}$ of railways and about 15,000 trains run daily for freight and passengers. Railway network failures must be imperatively controlled in order to maintain user and employee safety and to limit economic losses for the company, either direct cost (reconstruction works after an incident, delay compensations) or indirect cost (foregone revenues due to network unavailability, possible brand-image deterioration). Railway infrastructure is composed of multiple interacting elements such as the fixed installations for electric traction, the telecommunication installations, the traffic control installations, the tracks, the civil engineering structures, and the earthworks. Earthworks are built to get a steady longitudinal profile of the tracks and avoid the natural terrain fluctuations. Different transversal profiles can be created: embankments, when the tracks are above compacted material layers; excavations, when the tracks are below the natural terrain; mixed profiles, with an embankment on one side and an excavation on the other, and flat profiles when no particular earthwork is undertaken (Figure 1).

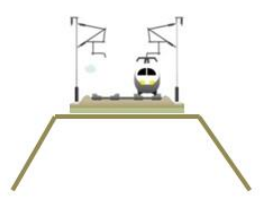

a. Embankment

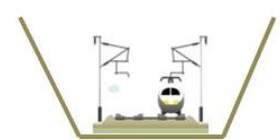

b. Excavation

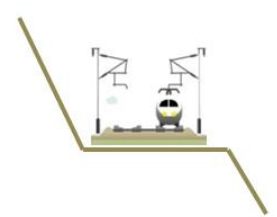

c. Mixed profile

Figure 1: Three types of transversal profiles of the railway infrastructure

Railways are exposed to water-related hazards since they cross natural water-flow paths (Chazelle et al., 2014). Water-related hazards can be classified into different types: fluvial flooding when rivers flow over their banks, coastal flooding when normally dry lands are flooded by sea water, ground water flooding when the ground water table level rises above the natural terrain, and pluvial flooding when rainfall generates floods on hillslopes outside the river network. This study focuses on pluvial flooding. When rainfall intensity exceeds soil infiltration capacity, water can flow over the ground surface (Beven, 2011; Dehotin et al., 2015a) and generate damage. Water surface runoff can reach high velocities and densities by carrying materials. This phenomenon is influenced by multiple factors (Le Bissonnais et al., 2005; Sivapalan et al., 1987): rainfall characteristics (intensity, duration, and frequency), soil surface characteristics such as topography, land use (agricultural and urban areas) and soil physical properties (type, permeability, erodibility, thickness). Once water is generated on the surface, it can flow downstream and generate various hazards such as floods, mudflows, shallow landslides, and erosion. 
Author-produced version of the article published in Safety science, 2018; 110 part B : 253-267

Railway infrastructure is particularly vulnerable to surface runoff given its characteristics. Electric installations may experience failure when impacted by water. The tracks are composed of ballast between the rails and the platform, which provide good mechanical properties but which can easily be swept away by water flows (Amblard et al., 2015). Earthworks are also vulnerable to surface runoff depending on their profile, length, slope or construction materials. They may experience erosion, landslides or destruction (Figure 2). In order to protect the infrastructure, railways are equipped with hydraulic structures. Their function is to ensure the natural water flows from upstream to downstream and to manage water generated within the railway right-of-way. Hydraulic structures can be transversal (aqueduct, nozzle, bridge) to make the water cross the railway. They can be longitudinal (ditches, drains, dikes) to pipe water towards an outlet. Retention basins can also be installed to dampen incoming and outgoing water volumes.
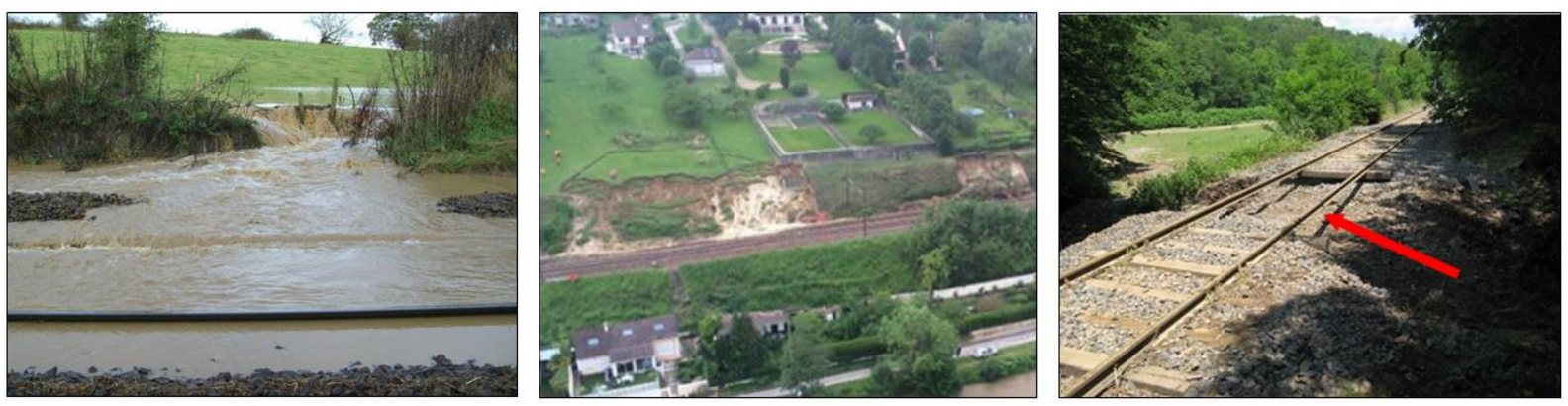

Figure 2: Illustration of surface runoff impacts on railways: from left to right, flood, landslide, and breach in the embankment

From an operational point of view, the risks for the railway network are disrupting train circulation and jeopardizing safety. Thus, risks induced by surface runoff are 1 / railway unavailability due to the presence of obstacles (water, materials), 2/ railway unavailability due to the absence of an element or of the whole railway (breach, destruction) and $3 /$ accelerated degradation of railway elements or railway stability. To manage these risks, actions must be undertaken at every railway life-stage: during new railway or new structure design, during maintenance, during operation by monitoring, during crisis phases, and after a crisis for recovery and feedback. However, surface runoff risk management generates technical issues as well as scientific issues.

\subsection{Technical issues}

Current issues in managing risks induced by surface runoff on railways lie in quantifying and qualifying surface runoff. Quantifying refers to a flow rate estimate at a catchment outlet and qualifying refers to a spatial assessment of areas where surface runoff is susceptible to occur. Flow rates are computed in order to dimension hydraulic structures or to verify they have a sufficient capacity. Surface runoff flow rate can be estimated for a catchment, thanks to historical discharge 
Author-produced version of the article published in Safety science, 2018; 110 part B : 253-267

data, by applying statistical methods on rainfall and runoff data. In nearly all cases, however, catchments intercepted by railways are ungauged. In this case, pseudo-empirical formula can be applied, such as the rational method (Thompson, 2007). The rational method allows computing the flow rate by multiplying the catchment area, the rainfall intensity, and a surface runoff coefficient. Uncertainties arise, amongst others, with the estimation of the surface runoff coefficient, which varies from 0 (totally permeable) to 1 (totally impervious), and which relies on expert opinion. Pseudo-empirical formulas are difficult to reproduce and not automated. So, they are difficult to apply for long railway sections. Moreover, peak flow rate is not the only representative variable for characterizing surface runoff since it can also carry mud and materials. This can clog hydraulic structures and significantly reduce their capacity. Moreover, the environment surrounding the railway is permanently evolving: land use can change (cultivation, urbanization), it can increase or deflect the incoming water volumes and existing hydraulic structures can become insufficient.

The surface runoff phenomenon itself is difficult to study and there is no hazard reference map available. There are different approaches in the scientific literature for surface runoff mapping. The approaches based on topography analysis only (Pons et al., 2010) are rather simple but they do not take into account the other parameters that influence surface runoff occurrence and intensity, such as land use or soil types. The approaches based on indicator combinations (Cerdan et al., 2006; Le Gouee et al., 2010) are more complex, but mainly focus on the erosion process and require accurate soil data, which are not available on a large scale. The approaches based on physical modelling (Dabney et al., 2011; Smith et al., 1995) are interesting since they can model the spatial and temporal dynamics at catchment scale, but they also require numerous input and calibration data and are hardly applicable on a large scale. Difficulties lie in the complexity of the surface runoff phenomenon. Surface runoff is generated by rainfall whose location and intensity are still difficult to forecast with current meteorological models. It is influenced by multiple factors and can occur in various forms (flood, erosion, mud). Thus, data from observations and measurements remain scarce, although they are essential to better understand the phenomenon and to calibrate and evaluate models. For these reasons, there is generally no mapping of the surface runoff hazard available on a national scale.

\subsection{Scientific issues}

A method called IRIP (for "Indicator of Intense Pluvial Runoff", French acronym) for surface runoff susceptibility mapping was developed by Dehotin and Breil (2011) from IRSTEA (French National Research Institute of Science and Technology for Environment and Agriculture). The IRIP method proposes an innovative approach for considering surface runoff. The method allows the creation of three maps representing three different phases of the surface runoff phenomenon: generation, transfer, and accumulation. The territory understanding is thus simplified by a spatial segmentation 
Author-produced version of the article published in Safety science, 2018; 110 part B : 253-267

130 of the dominant processes, and the risk management can be optimized by adapting the mitigation

131 techniques depending on the areas. The mapping method has been designed to be simple enough in order to be widely applicable, in particular in an operational context. It requires only three input data: a digital elevation model, a land use map, and a soil map. The IRIP method provides an operational method for surface runoff hazard mapping that can be used by regional organizations for land planning objectives. By sharing these issues in part with the railway infrastructure manager, the IRIP method has been adapted to the railway context in collaboration with SNCF Réseau. The maps created by the IRIP method are intended for use as a tool for decision-making. However, decisions can generate changes and induce costs in terms of planning or works, or affect safety aspects. Thus, decision-makers must be aware of the map interpretation rules, their range of application, and their uncertainties. For these reasons, the IRIP maps must be evaluated.

The scientific issue lies in the fact that, because of the surface runoff phenomenon complexity, there is no database of surface runoff observation or measurement available on a large scale to evaluate the surface runoff maps. So proxy data must be used for the evaluation. Proxy data are data which are not directly related to the physical phenomenon but which inform on the phenomenon occurrence, for example, data of surface runoff impacts. However, difficulties arise when comparing model outputs with proxy data because of the indirect relationship. Some studies used data of surface runoff impacts to evaluate or calibrate hydrologic models. Naulin et al. (2013) and Versini et al. (2010) used impact data on roads to evaluate and calibrate their flash-flood warning model. Defrance et al. (2014) and Javelle et al. (2014) used impact data to evaluate the performance of their flash-flood warnings. The IRIP method has also been evaluated by comparison with impact data on roads (Lagadec et al., 2016b) and on railways (Dehotin et al., 2015b; Lagadec et al., 2016a). During these evaluation tests, good probabilities of detection were obtained but also high false-alarm ratios because numerous areas where identified as susceptible to surface runoff but no impact has been recorded. For these studies, the major issue lies in characterizing the structural vulnerability of the transportation network, a key component when comparing hazards with effective impacts. For the same hazard intensity, the effective impact can be reduced by a low structural vulnerability or aggravated by a high structural vulnerability of the impacted network section. Use of proxy data also brings further uncertainties due to biases in the data exhaustiveness, representativeness, and location inaccuracy. So evaluation tests must go further in order to fully assess the IRIP method performance. 
Author-produced version of the article published in Safety science, 2018; 110 part B : 253-267

163

164

165

166

167

168

169

170

171

172

173

174

175

176

177

178

179

180

181

This paper has two objectives. The first one is to evaluate the surface runoff susceptibility maps created with the IRIP method by comparison with the results of a hydraulic diagnosis performed on a $20-\mathrm{km}$ stretch of railway. The evaluation focuses both on the performance of the IRIP method to detect railway sections exposed to surface runoff and on the relevance of the spatial information provided by the maps compared to the field reality. For this evaluation, the correspondence between the IRIP maps and the results of the hydraulic diagnosis is analyzed, taking into account the structural vulnerability of the railway infrastructure. The second objective is to provide practical solutions for integrating the IRIP method into the current risk assessment process in order to improve the management of surface runoff-related risks. Results of the IRIP method evaluation allow identifying specific tasks of the risk assessment process to which the IRIP method can make a direct contribution. Moreover, opportunities to improve risk reduction methods are discussed in the light of the new information brought by the IRIP method. The IRIP method development benefits from an industry-research partnership that makes it possible to go beyond a simple knowledge-to-application transfer, and enables the co-generation of new knowledge and new concepts for the two parts (Hatchuel et al., 2001; Klasing-Chen et al., 2017). Indeed, using data of the railway infrastructure manager allows evaluating the IRIP method and learning about the surface runoff physical phenomenon. Applying the IRIP method in an operational context makes it possible to identify possible new developments of the method to answer operational needs. Moreover, using an innovative mapping method opens up new possibilities for the management of surface runoff-related risks for the infrastructure manager.

\section{Materials and methods}

2.1.The hydraulic diagnosis of the Bréauté to Fécamp railway line The Bréauté to Fécamp railway, located in the Normandy region, is line 359000 of the French railway network. The Bréauté to Fécamp railway is $20 \mathrm{~km}$ long. It is a single track line, non-electrified with a maximum speed limit of $80 \mathrm{~km} / \mathrm{h}$. The railway connects the city of Bréauté, on the Paris-to-Le Havre railway axis, to the port city of Fécamp. The railway was put into operation in 1856. Regarding the hydrological context, the railway intercepts several catchments with a total area of about $55 \mathrm{~km}^{2}$, an altitude ranging from 6 to $146 \mathrm{~m}$ ASL (Above Sea Level). The area is composed of large plateaus (south and start of the line) and a narrow valley (north and end of the line) (Figure 3). The catchment soil is mainly composed of silt and clay on the plateaus, with colluvial deposit in the valley and the bedrock is composed of chalk and flint stones. There is no perennial river in the catchment but intermittently, during rainfall, small streams can be activated within the main valleys. The land use is 
Author-produced version of the article published in Safety science, 2018; 110 part B : 253-267

The Seine-Maritime County

202 intercepted by the railway

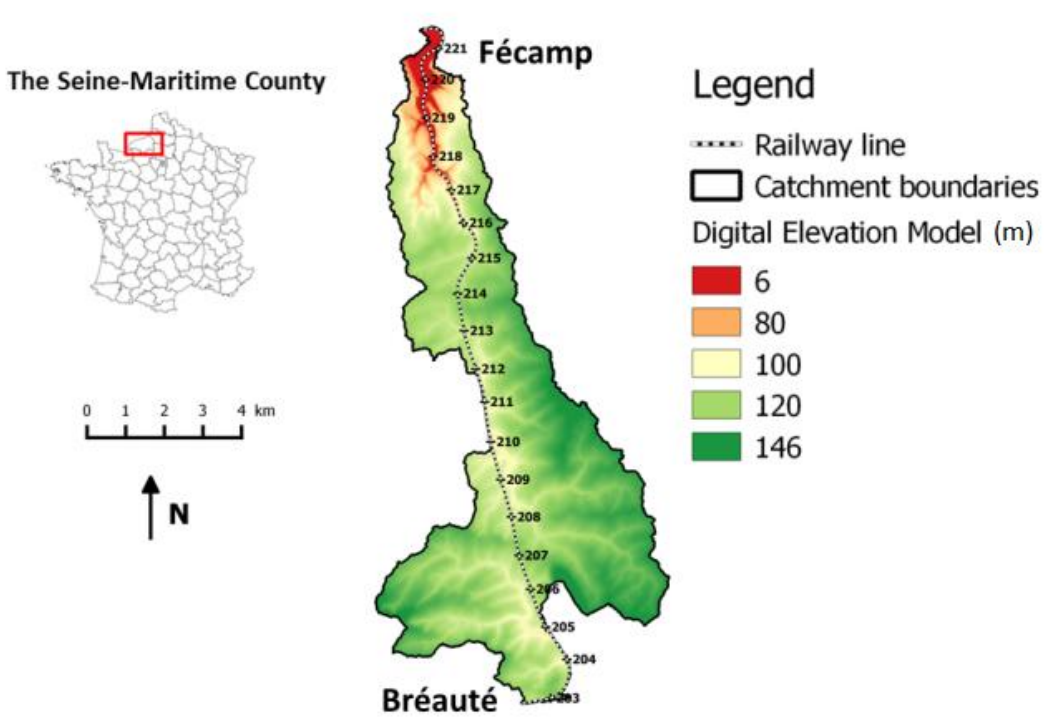

dominated by agriculture with rural households and the small city of Fécamp in the north has about 20,000 inhabitants. Due to its age, its location, and a low traffic level, this railway has been suffering from an advanced level of deterioration. To ensure safety aspects, the railway traffic was slowed, from 80 to $60 \mathrm{~km} / \mathrm{h}$, then to $40 \mathrm{~km} / \mathrm{h}$, and then was stopped. In the context of an Infrastructure and Transport Regional Plan adopted by the Normandy region in 2009, the Bréauté to Fécamp railway has been identified as a substantial means of transportation for regional development. Since then, several analyses have been undertaken to optimize regeneration works.

Figure 3: The study area which includes the railway from Bréauté to Fécamp and all the catchments

In this context of line regeneration, a railway line diagnosis was carried out in order to decide and prioritize works. All the infrastructure elements were considered, from the platform, the rails, to the earthworks and to the hydraulic structures. For the present paper, to evaluate the IRIP method, we focus on the hydraulic studies. Due to the important constraints in terms of budget and time during the diagnosis, the study only focused on drainage regeneration works. Hydraulic structures crossing under the railway or retention basins were not studied. The diagnosis consists of assessing the level of hazard exposure, and of assessing the capacity of the existing drainage structures, regarding their level of deterioration. In a second step, recommendations were provided in terms of drainage design and monitoring strategies. To this purpose, the Bréauté-Fécamp railway line was divided into 61 sections depending on their transversal profile type (embankment, excavation, mixed profile). This division choice is consistent from a hydraulic point of view. The interaction type between the natural 
Author-produced version of the article published in Safety science, 2018; 110 part B : 253-267

surface runoff and the infrastructure strongly depends on the type of transversal profile. Among these 61 sections, 17 have been selected for drainage regeneration works.

The results of the study performed on the Bréauté-Fécamp railway line do not only reflect the level of surface runoff hazard exposure along the line, but is a combination of the risk assessment and the budget, time and feasibility constraints. Recommendations for hydraulic works were required by the infrastructure manager to respect certain constraints such as a lack of space for implementing the sufficient drainage structures regarding the estimated flow rates and the mud inflows; time constraints of the work period, which hindered feasibility studies for works outside the railway rightof-way and made it impossible to establish special procedures for water legislation which would have taken too much time; and budget constraints, which obliged the study to focus only on the drainage structures and not on the hydraulic structure crossing under the railway or other structures such as retention basins. The study results however provide meaningful information about potential storm runoff coming from the surrounding environment, and a fair source of comparison for the IRIP maps.

\subsubsection{Description} The IRIP method is described briefly here, but further information can be found in the literature (Dehotin and Breil, 2011a; Lagadec et al., 2016b). The IRIP method combines indicators from geographic information layers and produces three maps representing three processes of storm runoff (Figure 4, Table 1): generation, representing areas with low infiltration capacity and which are susceptible to generate water at ground surface; transfer, representing areas where surface water can move downward, accelerate, and erode soils; and accumulation, representing areas where surface runoff can concentrate following topography, where it can slow down and generate floods out of rivers and deposits. Each map is created by combining five indicators. Each indicator is classified into two categories: favorable, where 1 is attributed to the pixel, or not favorable, where 0 is attributed. This yields 5 binary maps. The maps are added to create a susceptibility map with 6 levels, from 0 (not susceptible) to 5 (very susceptible). For each of the three susceptibility maps, the 5 indicators are different. The generation map is created thanks to three indicators derived from a soil map, one indicator derived from a land use map, and one derived from the topography. The latter is a combination of the slope and the topographic index (Beven and Kirkby, 1979): 1 if both are favorable, 0 if one is not favorable. The generation map is then considered as an input indicator for the two other maps of transfer and accumulation in order to represent the necessity for the surface water to be generated before being transferred and/or accumulated. Maps of transfer and accumulation are created mainly by associating indicators based on topography, but with opposed favorability conditions, in order to represent the opposed movement of acceleration and slowdown. 
250 For example, the slope indicator is favorable for transfer in the case of steep slopes, and for

251 accumulation in the case of low slopes. The break of slope indicator is favorable for transfer in the

252 case of convex break of slopes and for accumulation in the case of concave break of slopes.

253 Topographic indicators are computed for each pixel relatively to the upstream sub-catchment in order to follow the hydrological logic from upstream to downstream. The resolution of the susceptibility maps retains the resolution of the Digital Elevation Model (rasterized topography map) used as input data. To determine the favorability thresholds for topographic indicators, a classification method is used (Rubin, 1967), in order to compute a relative threshold depending on knowledge.

\section{GENERATION}

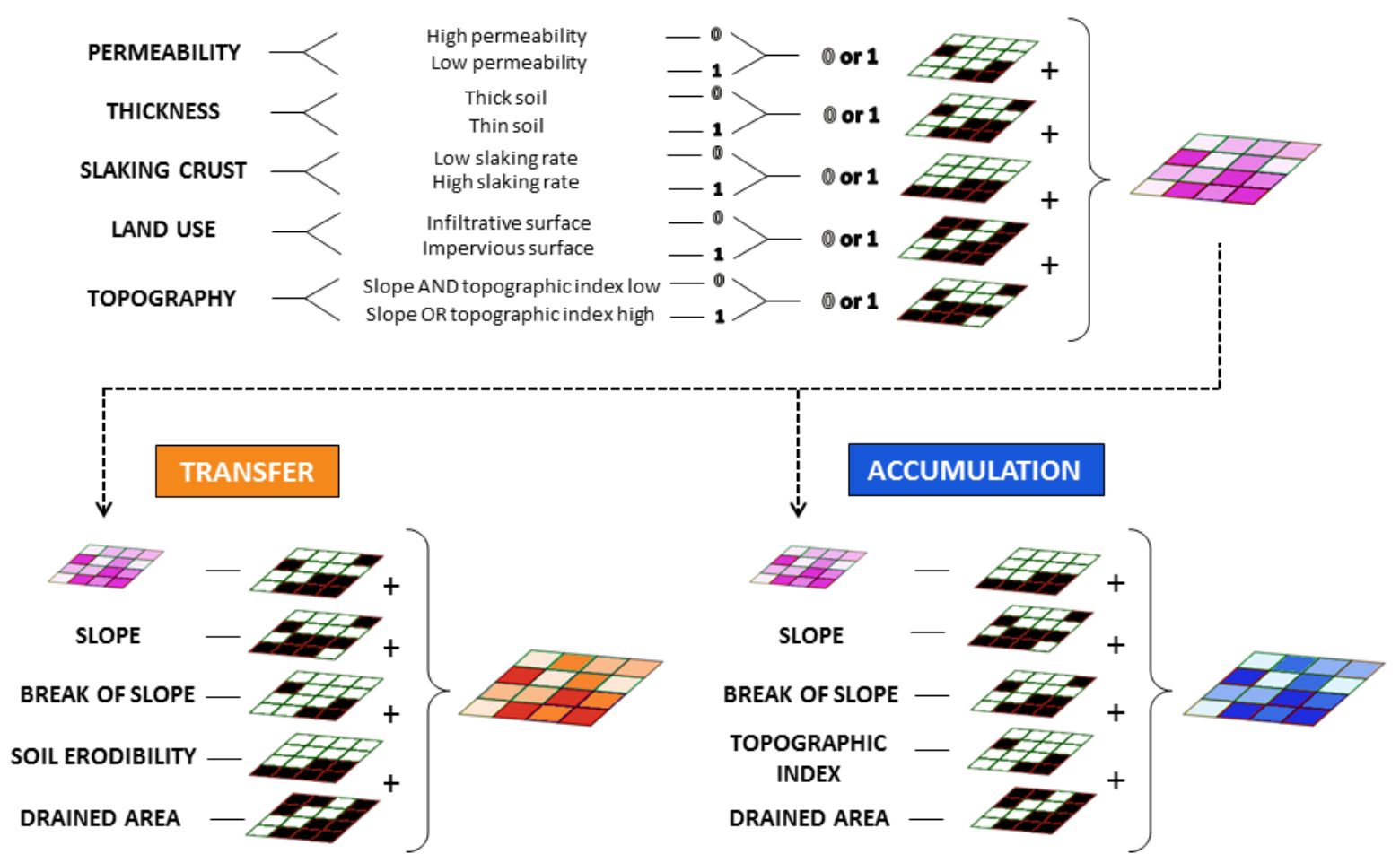


Table 1: List of the indicators used in the IRIP method along with their conditions of favorability to surface runoff

\begin{tabular}{|c|c|c|}
\hline IRIP maps & Indicators & Conditional values \\
\hline \multirow{10}{*}{ Generation } & \multirow{2}{*}{ Soil permeability } & 0: Saturated hydraulic conductivity $(\mathrm{Ks}) \geq 1 \mathrm{e}-6 \mathrm{~m} / \mathrm{s}$ \\
\hline & & 1: $\mathrm{Ks}<1 \mathrm{e}-6 \mathrm{~m} / \mathrm{s}$ \\
\hline & \multirow{2}{*}{ Soil thickness } & $0:$ Thickness $\geq 50 \mathrm{~cm}$ \\
\hline & & 1: Thickness $<50 \mathrm{~cm}$ \\
\hline & \multirow{2}{*}{ Soil crustability } & 0: Crustability < 3 (Cerdan et al., 2006) \\
\hline & & 1: Crustability $\geq 3$ \\
\hline & \multirow{2}{*}{ Topography } & $\begin{array}{l}0: \text { Slope } \leq 0.5 \% \text { AND topographic index } \leq \text { (mean }+ \\
\text { standard deviation) }\end{array}$ \\
\hline & & $\begin{array}{l}\text { 1: Slope }>0.5 \% \text { OR topographic index }>\text { (mean }+ \\
\text { standard deviation) }\end{array}$ \\
\hline & \multirow{2}{*}{ Land use } & 0: Pastures, grasslands, and forests \\
\hline & & 1: Urban areas and agricultural lands \\
\hline \multirow{10}{*}{ Transfer } & \multirow{2}{*}{$\begin{array}{c}\text { Upstream } \\
\text { generation } \\
\text { susceptibility }\end{array}$} & 0 : Modal value of the upstream sub-catchment $<3 / 5$ \\
\hline & & 1: Modal value of the upstream sub-catchment $\geq 3 / 5$ \\
\hline & \multirow{2}{*}{ Slope } & 0: Slope $\leq 5 \%$ \\
\hline & & 1: Slope > 5\% \\
\hline & \multirow{2}{*}{ Break of slope } & 0: Concave break of slope \\
\hline & & 1: Convex break of slope \\
\hline & \multirow{2}{*}{ Drained area } & 0: Drained area $\leq$ (mean + standard deviation $)$ \\
\hline & & 1: Drained area > (mean + standard deviation) \\
\hline & \multirow{2}{*}{ Soil erodibility } & $0:$ Erodibility $<3$ \\
\hline & & 1: Erodibility $\geq 3$ \\
\hline \multirow{10}{*}{ Accumulation } & \multirow{2}{*}{$\begin{array}{c}\text { Upstream } \\
\text { generation } \\
\text { susceptibility }\end{array}$} & 0 : Modal value of the upstream sub-catchment $<3 / 5$ \\
\hline & & 1: Modal value of the upstream sub-catchment $\geq 3 / 5$ \\
\hline & \multirow{2}{*}{ Slope } & $0:$ Slope $>5 \%$ \\
\hline & & 1: Slope $\leq 5 \%$ \\
\hline & \multirow{2}{*}{ Break of slope } & 0: Convex break of slope \\
\hline & & 1: Concave break of slope \\
\hline & \multirow{2}{*}{ Topographic index } & 0: Topographic index $\leq$ (mean + standard deviation) \\
\hline & & 1: Topographic index $>$ (mean + standard deviation $)$ \\
\hline & \multirow{2}{*}{ Drained area } & 0: Drained area $\leq$ (mean + standard deviation $)$ \\
\hline & & 1: Drained area $>$ (mean + standard deviation $)$ \\
\hline
\end{tabular}

\footnotetext{
${ }^{1}$ IGN Website : http://professionnels.ign.fr/
} 
Author-produced version of the article published in Safety science, 2018; 110 part B : 253-267

database (Ballabio et al., 2016), and the regional land use map ${ }^{2}$ at a scale of $1 / 5000$ in rural areas and $1 / 2000$ in urban areas. Because high resolution input data were available and previous works had been conducted in the Seine-Maritime County with the IRIP method (Lagadec et al., 2016b), a specific parameterization of the method was proposed for this study. Two indicators were adapted along with some favorability thresholds, which are the condition for a pixel to be set at 1 or 0 . Concerning the indicators, because of a strong disposition of the soil to slaking crust in this region (Cerdan et al., 2002), a slaking indicator was used in the generation map, instead of the erodibility indicator. The erodibility indicator was used in the transfer map to highlight the erosion mechanism, which is important in this territory. The erodibility indicator replaces the ground linear axes in the transfer map. The ground linear axis indicator is used in the case of coarse resolution DEM, in order to represent the effect of interception and redirection of surface runoff by roads, agricultural drainage or even railways ( 1 for presence of a linear axis, otherwise 0 ). For this study, the use of a Lidar DEM allows the detection of this kind of ground axes, so their effects of interception and redirection are directly taken into account within the topographic indicators.

Concerning the favorability thresholds, they are summarized in Table 1. A soil is considered as having low infiltration capacity for saturated hydraulic conductivity lower than $10^{-6} \mathrm{~m} / \mathrm{s}$. A soil is considered as thin, and thus with a low storage capacity, for a thickness lower than $50 \mathrm{~cm}$. The thresholds for soil slaking ability and erodibility are set at 3 with respect to the pedo-transfer rules (Cerdan et al., 2006). These thresholds are set by default in the IRIP method and are based on a literature review in the pedology field (Dehotin and Breil, 2011a, 2011b). For this study, the thresholds that are adjusted for the study area are those for the slope, the topographic index, and the drained area indicators. The threshold of $5 \%$ was chosen thanks to discussions with local actors (SMBV Pointe de Caux ${ }^{3}$ ), who generally observe intense surface runoff on about $5 \%$ slopes. A threshold of $0.5 \%$ is chosen for the generation map, because below $0.5 \%$ the area is considered flat and surface runoff can infiltrate into the soil. The thresholds of topographic index and drained areas are set at the mean plus the standard deviation of the range of values over the study area, instead of using the classification method. The classification method provides good results for coarser resolution DEM, but for this study using a very high resolution DEM modifies the range of values, and the threshold must be more restrictive to display less information and to simplify the interpretation of the maps. Note that the hydraulic structures are not taken into account in the IRIP method, in particular those under the railway that do not appear in the DTM.

\footnotetext{
${ }^{2}$ Website to download the regional land use map and further information about its creation: http://mos.hautenormandie.fr/

${ }^{3}$ SMBV Pointe de Caux: Mixed association of the Pointe de Caux Region
} 
Author-produced version of the article published in Safety science, 2018; 110 part B : 253-267

2.3. Comparison method of the IRIP maps and the hydraulic diagnosis results The objective of the comparison is to evaluate the performance of the IRIP method to retrieve railway sections exposed to surface runoff. Two types of comparisons are performed: a quantitative comparison over the whole line, using statistical methods; and a qualitative comparison on three railway sections to assess the relevance of the spatial information over the catchment.

\subsubsection{Quantitative comparison}

In this part, the question we want to address is: are the highest susceptibility levels of the IRIP maps located on the railway sections selected for regeneration works? In other words, what is the Correspondence rate between the IRIP maps and the hydraulic diagnosis results, over the whole railway line? To answer this question, the railway was divided into 3 types of transversal profile (embankment, excavation, and mixed profile) following the division performed during the hydraulic diagnosis. For each profile type, the following information was summarized: its length (in meters), the presence of an aperture under the railway (bridge or hydraulic structure), and whether or not the section was selected for regeneration works. Concerning the IRIP information, the following information was computed for each profile type: the number of pixels greater than or equal to $4 / 5$ for the maps of transfer and accumulation that are located within a buffer area of 5 meters both sides of the railway. This 10-meter width of analysis was chosen in order to take into account the track, which is a single track, the sidetracks, and a part of the earthworks. As it is difficult to state from which level of exposure a railway is susceptible to suffer damage, two hypotheses were tested to consider a railway section detected by IRIP as exposed to surface runoff or not: condition no. 1, at least 1 pixel of the transfer or the accumulation map greater than or equal to $4 / 5$ located within the $10-\mathrm{m}$ buffer area; and condition no. 2 , at least $10 \%$ of the linear of the railway section is covered by pixels transfer or accumulation greater than or equal to $4 / 5$. This ratio was computed by the sum of the pixel numbers of accumulation and transfer, multiplied by 5 (the length of a pixel), divided by the section linear, and multiplied by 100 to get a percentage. This allowed having a rather permissive condition (the first), and a more binding condition (the second).

To analyze the performance of the IRIP method, contingency tables were created and verification indicators were computed. A contingency table is a matrix that represents the interrelation between two variables (Hogan and Mason, 2012; Stanski et al., 1989). For this study, contingency tables were computed between the number of sections that are detected by IRIP or not (lines) and the number of sections that are selected for works or not (columns) (Table 2 ). The true positives $(T+$ ) are sections which are detected by IRIP and selected for regeneration works. The false positives $(\mathrm{F}+)$ are sections which are detected by IRIP but not selected for works. The false negatives (F-) are sections which are not detected by IRIP but are selected for works. And the true negatives (T-) are sections which are 
Author-produced version of the article published in Safety science, $2018 ; 110$ part B : 253-267

not detected by IRIP and not selected for works. Table 3 presents the indicators used for evaluating the IRIP method performance. The probability of detection (POD) and the false alarm ratio (FAR) are computed from the contingency tables. The best score is for a greatest POD combined with a lowest FAR. In addition to this, Chi-Square tests are performed for each contingency table in order to assess the statistical significance of the contingency tables. A Chi-Square test allows the assessment of the statistical dependence between the IRIP maps and the diagnosis results, by comparing the observed headcount of the contingency table to headcount got with a hypothesis of total independence. For example, according to the tabulated Chi-Square values, if the computed Chi-Square is above 6.63, it means that the probability of independence between the IRIP maps and the diagnosis results is less than $1 \%$. Finally, the false negatives and the false positives were explained through a brief assessment of the vulnerability.

Table 2: The theoretical contingency table representing the interrelation between the number of sections detected by IRIP and the number of sections selected for work

\begin{tabular}{|c|c|c|c|}
\cline { 3 - 4 } \multicolumn{2}{c|}{} & \multicolumn{2}{c|}{ Selected for work } \\
\cline { 3 - 4 } \multicolumn{2}{c|}{} & Yes & No \\
\hline \multirow{2}{*}{$\begin{array}{c}\text { Detected } \\
\text { by IRIP }\end{array}$} & Yes & T+ & F+ \\
\cline { 2 - 4 } & No & F- & T- \\
\hline
\end{tabular}

Table 3: Summary of the indicators used to evaluate the IRIP method performance along with their equation and interpretation.

\begin{tabular}{|c|c|c|}
\hline Indicators & Equations & Interpretation \\
\hline \multirow{2}{*}{ POD } & $\frac{(T+)}{(T+)+(F-)}$ & $\begin{array}{c}\text { Range: } 0-1 \\
\text { Best score: } 1\end{array}$ \\
\hline \multirow{2}{*}{ FAR } & $\frac{(F+)}{(F+)+(T+)}$ & $\begin{array}{c}\text { Range: } 0-1 \\
\text { Best score: } 0\end{array}$ \\
\hline \multirow{5}{*}{ Chi-Square } & $\sum \frac{(O-E)^{2}}{E}$ & $\begin{array}{c}\text { For } 1 \text { degree of freedom: } \\
\mathrm{P}\left(\mathrm{X}_{2}>6.63\right)=0.01\end{array}$ \\
& $\mathrm{O}=$ Observed headcounts & $\mathrm{P}\left(\mathrm{X}_{2}>7.88\right)=0.005$ \\
& $\mathrm{E}=$ Expected headcounts & $\mathrm{P}\left(\mathrm{X}_{2}>10.83\right)=0.001$ \\
\hline
\end{tabular}

\subsubsection{Qualitative comparison}

In this part, the question we want to answer is: do the field observations and the recommendations fit with the spatial information of the IRIP maps of transfer and accumulation? In other words, on which map and in which forms is the information from the field retrieved? The relevancy of the IRIP maps is assessed in terms of location of the preferential water flow paths, of areas susceptible to surface water accumulation and susceptible to erosion, and in terms of IRIP susceptibility levels. 
Author-produced version of the article published in Safety science, 2018; 110 part B : 253-267

357 Schemes from the hydraulic diagnosis are used to perform the comparisons. For each section

358 selected for works, the schemes represent the recommended measures along with the field 359 observations. The comparison is visual and qualitative because it displays the two maps, IRIP and the diagnosis, of the same area side by side. Photos from the field allow supporting identification of matching areas. Although all railway sections analyzed in the diagnosis were compared to IRIP maps, this paper presents four sections. Two of them illustrate mainly the contribution of the accumulation susceptibility map and the other two illustrate mainly the contribution of the transfer susceptibility map. Finally, some patterns of storm runoff spatial dynamics and railway infrastructure configuration can be identified from this comparison as being a configuration at risk. So interpretation guidelines of the IRIP maps are provided in order to support forthcoming risk assessment of railway lines.

Table 4: List of the 61 railway sections along with their type of transversal profile (Emb: Embankment, Exc: Excavation, MP: Mixte Profile), their length, whether or not they have been selected for drainage regeneration works, the number of pixels with susceptibility levels greater than or equal to $4 / 5$ in transfer and in accumulation, the ratio of the number of pixel and the length, whether or not the section has been detected by IRIP according to 2 conditions and whether or not there is an aperture under the railway. 


\begin{tabular}{|c|c|c|c|c|c|c|c|c|c|}
\hline No. & Type & $\begin{array}{l}\text { Linear } \\
(\mathrm{m})\end{array}$ & $\begin{array}{c}\text { Selected } \\
\text { for } \\
\text { works }\end{array}$ & $\begin{array}{c}\sum \text { Acc } \\
4 \& 5\end{array}$ & $\begin{array}{c}\Sigma \text { Trans } \\
4 \& 5\end{array}$ & $\begin{array}{c}\text { Ratio } \\
\text { IRIP/linear } \\
(\%)\end{array}$ & $\begin{array}{c}\text { Detected } \\
\text { by IRIP } \\
\text { Condition } 1\end{array}$ & $\begin{array}{c}\text { Detected } \\
\text { by IRIP } \\
\text { Condition } 2\end{array}$ & $\begin{array}{c}\text { Aperture } \\
\text { under the } \\
\text { railway }\end{array}$ \\
\hline 1 & Emb & 230 & no & 0 & 0 & 0 & no & no & no \\
\hline 2 & Emb & 225 & no & 3 & 8 & 24 & yes & yes & yes \\
\hline 3 & Exc & 1020 & yes & 70 & 0 & 34 & yes & yes & no \\
\hline 4 & Emb & 30 & no & 1 & 0 & 17 & yes & yes & yes \\
\hline 5 & Exc & 290 & no & 22 & 0 & 38 & yes & yes & no \\
\hline 6 & Emb & 520 & no & 0 & 0 & 0 & no & no & no \\
\hline 7 & Exc & 340 & yes & 29 & 0 & 43 & yes & yes & no \\
\hline 8 & $\mathrm{Emb}$ & 470 & no & 0 & 0 & 0 & no & no & no \\
\hline 9 & Exc & 1010 & yes & 129 & 0 & 64 & yes & yes & no \\
\hline 10 & Emb & 520 & no & 1 & 1 & 2 & yes & no & yes \\
\hline 11 & Exc & 1250 & yes & 91 & 1 & 37 & yes & yes & no \\
\hline 12 & Emb & 650 & no & 2 & 2 & 3 & yes & no & yes \\
\hline 13 & Exc & 200 & no & 0 & 0 & 0 & no & no & no \\
\hline 14 & Emb & 250 & no & 1 & 2 & 6 & yes & no & yes \\
\hline 15 & Exc & 100 & no & 0 & 0 & 0 & no & no & no \\
\hline 16 & Emb & 50 & no & 2 & 0 & 20 & yes & yes & yes \\
\hline 17 & Exc & 440 & no & 24 & 0 & 27 & yes & yes & no \\
\hline 18 & $\mathrm{Emb}$ & 250 & no & 0 & 2 & 4 & yes & no & yes \\
\hline 19 & Exc & 250 & no & 5 & 0 & 10 & yes & yes & no \\
\hline 20 & Emb & 460 & no & 0 & 1 & 1 & yes & no & yes \\
\hline 21 & Exc & 300 & no & 11 & 0 & 18 & yes & yes & no \\
\hline 22 & Emb & 200 & no & 1 & 1 & 5 & yes & no & yes \\
\hline 23 & Exc & 500 & yes & 28 & 0 & 28 & yes & yes & no \\
\hline 24 & Emb & 570 & no & 0 & 0 & 0 & no & no & no \\
\hline 25 & Exc & 500 & no & 25 & 0 & 25 & yes & yes & no \\
\hline 26 & Emb & 150 & no & 0 & 0 & 0 & no & no & no \\
\hline 27 & Exc & 300 & no & 4 & 0 & 7 & yes & no & no \\
\hline 28 & Emb & 330 & no & 2 & 2 & 6 & yes & no & yes \\
\hline 29 & Exc & 1200 & yes & 130 & 0 & 54 & yes & yes & no \\
\hline 30 & Emb & 200 & yes & 32 & 2 & 85 & yes & yes & no \\
\hline 31 & Exc & 200 & yes & 26 & 1 & 68 & yes & yes & no \\
\hline 32 & Emb & 150 & no & 0 & 0 & 0 & no & no & no \\
\hline 33 & Exc & 550 & yes & 54 & 24 & 71 & yes & yes & no \\
\hline 34 & Emb & 100 & no & 1 & 1 & 10 & yes & yes & yes \\
\hline 35 & Exc & 830 & yes & 46 & 0 & 28 & yes & yes & no \\
\hline 36 & $\mathrm{MP}$ & 330 & yes & 3 & 38 & 62 & yes & yes & no \\
\hline 37 & Emb & 120 & no & 2 & 1 & 13 & yes & yes & yes \\
\hline 38 & $\mathrm{MP}$ & 260 & no & 0 & 0 & 0 & no & no & no \\
\hline 39 & Emb & 110 & no & 0 & 0 & 0 & no & no & no \\
\hline 40 & Exc & 410 & yes & 1 & 17 & 22 & yes & yes & no \\
\hline 41 & Emb & 150 & no & 0 & 0 & 16 & no & no & no \\
\hline 42 & Exc & 160 & no & 28 & 23 & 159 & yes & yes & yes \\
\hline 43 & Emb & 110 & no & 1 & 2 & 14 & yes & yes & yes \\
\hline 44 & Exc & 250 & yes & 0 & 4 & 8 & yes & no & no \\
\hline
\end{tabular}




\begin{tabular}{|c|c|c|c|c|c|c|c|c|c|}
\hline 45 & Emb & 270 & no & 0 & 5 & 9 & yes & no & no \\
\hline 46 & $\mathrm{MP}$ & 230 & no & 0 & 14 & 30 & yes & yes & no \\
\hline 47 & Emb & 100 & no & 2 & 2 & 20 & yes & yes & yes \\
\hline 48 & $\mathrm{MP}$ & 80 & no & 0 & 0 & 0 & no & no & no \\
\hline 49 & Emb & 110 & no & 2 & 1 & 14 & yes & yes & yes \\
\hline 50 & Exc & 190 & yes & 0 & 1 & 3 & yes & no & no \\
\hline 51 & Emb & 70 & no & 2 & 1 & 21 & yes & yes & yes \\
\hline 52 & Exc & 200 & no & 0 & 3 & 8 & yes & no & no \\
\hline 53 & Emb & 150 & no & 2 & 2 & 13 & yes & yes & yes \\
\hline 54 & $\mathrm{MP}$ & 100 & no & 0 & 0 & 0 & no & no & no \\
\hline 55 & Emb & 90 & no & 2 & 0 & 11 & yes & yes & yes \\
\hline 56 & Exc & 400 & yes & 24 & 0 & 30 & yes & yes & no \\
\hline 57 & Emb & 60 & yes & 1 & 2 & 25 & yes & yes & yes \\
\hline 58 & Exc & 1100 & yes & 16 & 21 & 17 & yes & yes & no \\
\hline 59 & Emb & 150 & no & 0 & 0 & 0 & no & no & no \\
\hline 60 & Exc & 320 & no & 1 & 0 & 2 & yes & no & no \\
\hline 61 & Emb & 130 & no & 11 & 0 & 42 & yes & yes & no \\
\hline
\end{tabular}

For this comparison, the railway is divided into 61 sections which represent the different profile types: embankment, excavation, and mixed profile. Sections range from 30 to $1250 \mathrm{~m}$, with a mean length of about $350 \mathrm{~m}$. Table 4 presents the information for each section. The number of sections per type of correspondence ( $\mathrm{T}+, \mathrm{F}+, \mathrm{F}$ - and $\mathrm{T}-)$ is counted from this table. They are summarized in Table 5. The first column of Table 5 presents the correspondences between the column "detected by IRIP condition 1" and the column "selected for works" of Table 4. The second column presents the correspondences between "detected by IRIP condition 2" and "selected for works". Then POD, FAR, and Chi-Square are computed for each column. For condition no. 1, the less binding, a score of $100 \%$ of POD is obtained, which means that all the sections detected by the IRIP method are indeed selected for drainage works. This POD is promising but must be analyzed with the associated FAR, which is here $65 \%$. This means that $65 \%$ of all the sections detected by IRIP are not selected for works. Considering condition no. 2, which means a ratio IRIP/linear greater than or equal to 10, POD remains rather high at $88 \%$, but FAR decreases to $56 \%$. For both conditions, the Chi-Square test states that these headcounts are significant with probabilities of being due to chance of $1 \%$ and $0.01 \%$ respectively. To continue analyzing the IRIP method performance, the FAR percentages, which are sections with a false positive correspondence, are further investigated. 
Table 5: Number of railway sections among the 61 for each type of correspondence along with the POD, FAR, and Chi-Square, for the 2 conditions for a section being detected by the IRIP method and considering the infrastructure configuration or not.

\begin{tabular}{|c|c|c|c|c|}
\cline { 2 - 5 } \multicolumn{1}{c|}{} & \multicolumn{2}{c|}{$\begin{array}{c}\text { Without considering railway } \\
\text { configuration }\end{array}$} & \multicolumn{2}{c|}{$\begin{array}{c}\text { Considering railway } \\
\text { configuration }\end{array}$} \\
\cline { 2 - 5 } & $\begin{array}{c}\text { Condition no. } \\
1\end{array}$ & Condition no. 2 & Condition no. 1 & Condition no. 2 \\
\hline T+ & 17 & 15 & 35 & 33 \\
\hline F+ & 30 & 19 & 12 & 8 \\
\hline F- & 0 & 2 & 0 & 2 \\
\hline T- & 14 & 25 & 14 & 18 \\
\hline POD & 1 & 0.88 & 1 & 0.94 \\
\hline FAR & 0.65 & 0.56 & 0.26 & 0.2 \\
\hline Chi-Square & 7.02 & 10.09 & 24.46 & 27.31 \\
\hline
\end{tabular}

Among all the 61 railway sections, some sections are exposed to surface runoff according to the IRIP maps but they were not selected for works after the hydraulic diagnosis. Their transversal profile is an embankment equipped with an aperture under the railway (for example, railway sections no. 2 , 12 or 28). It can be considered that these sections are not vulnerable. Moreover, it can be considered that if there is an aperture under the railway, this is due to the necessity to allow surface runoff to flow down, and that the exposure to surface runoff is effective. Railway sections with this type of configuration, embankment and aperture, can thus be converted from false positive to true positive. New correspondences are computed and are presented in the two last columns of Table 5 along with their POD, FAR, and Chi-Square. The result is a decrease of the FAR, from 65 to $26 \%$ for condition no. 1 , and from 56 to $20 \%$ for condition no. 2 . It is also interesting to notice a very high POD of $94 \%$ for condition no. 2, which is the most binding one. The Chi-Square tests state that these results are statistically very significant (24.46 and 27.31). Explanations for the false negatives and the remaining false positive are provided below.

\subsubsection{Analysis of the false negatives and the false positives}

First, we will focus on false negatives, which are railway sections no. 44 and 50 (Figure 5). Railway section no. 44 is a deep excavation up to 15 meters high with woody vegetation. This earthwork is considered to be fragile and is subject to particular attention since an important landslide occurred on the left side. During a field visit, water stagnation was observed on the tracks, and the current draining ditches were clogged by mud. These explanations actually fit with the IRIP map. Transfer susceptibility levels of $4 / 5$ are located all over the left side of the excavation, where the landslide occurred, and accumulation susceptibility levels of $3 / 5$ are located on the tracks where water 
Author-produced version of the article published in Safety science, 2018; 110 part B : 253-267

stagnation was observed. The other example, railway section no. 50, is an excavation up to 3 meters high and with an upstream surrounding of wood and grassland. This section was selected because a few shallow landslides have occurred on the left side. The hydraulic diagnosis stated that the landslides could have been influenced by rabbit holes. This can indeed aggravate consequences when surface runoff occurs but also can induce landslide by itself. It has been decided to create open ditches to help evacuate water. This earthwork has a transfer susceptibility level of $4 / 5$ computed by the IRIP method. These examples show that, in some cases, high susceptibility levels of transfer must be taken into account not only when they are directly located on the tracks but also when they are on the earthwork sides. Moreover, in the case of railway section no. 44, accumulation susceptibility levels of 3 could also be considered for water stagnation issues. These two cases fit globally with the IRIP maps, but do not satisfy any of the two conditions stated for a railway section being considered as exposed to surface runoff according to the IRIP method. These cases illustrate how the IRIP pixel configuration along with their susceptibility levels could indicate an exposure to different types of surface runoff impacts (landslide, water stagnation, mudflow, flood...). For example, the quantity of stagnant water could be verified in the field to propose an eventual relationship with the IRIP susceptibility levels. Further tests should be performed to go further with this suggestion.

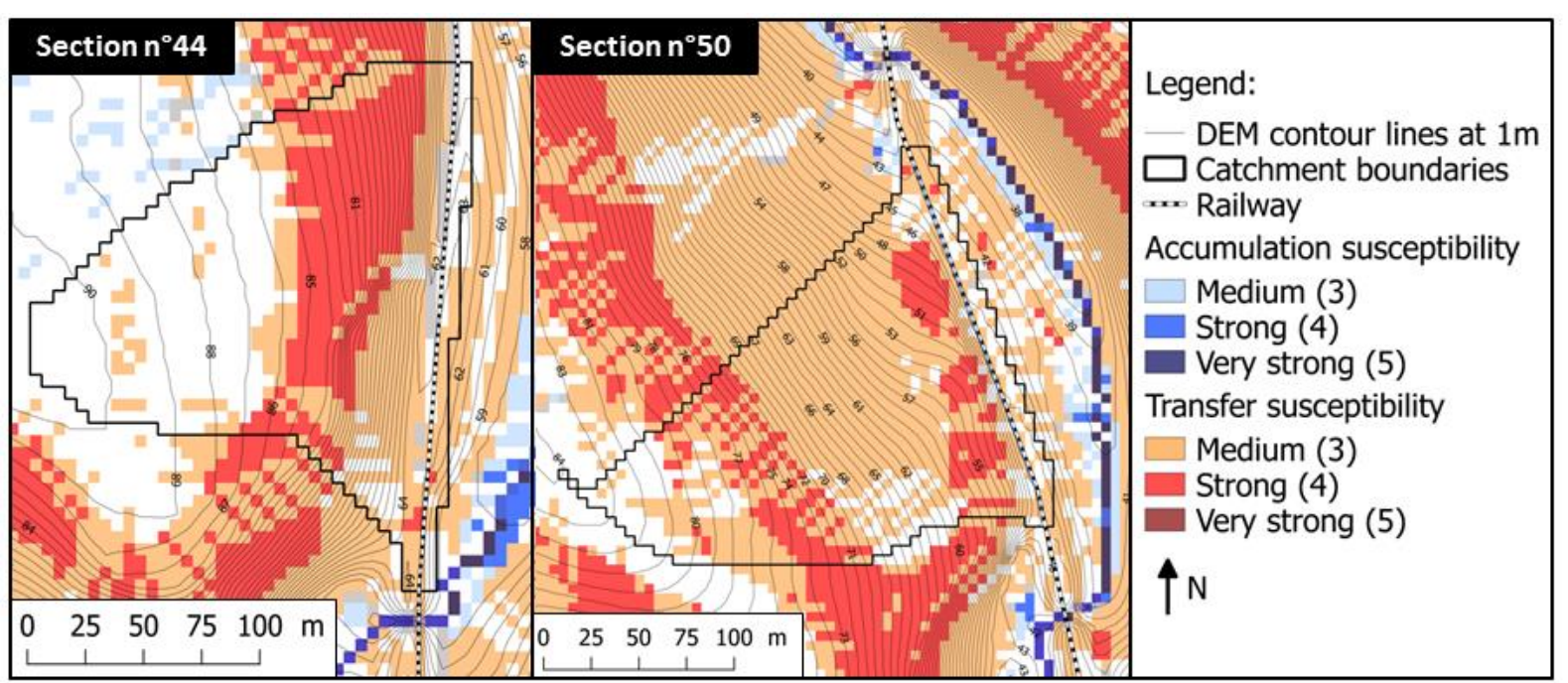

Figure 5: The two false negatives correspondences, where the conditions to consider a railway section as exposed to surface runoff, according to IRIP, are not satisfied but where regeneration works have been recommended.

False positives represent 12 railway sections with condition no. 1 and 8 railway sections with condition no. 2. These false positives mean that the IRIP method detects an exposure of the railway to surface runoff but that no regeneration works were undertaken. Among the 8 remaining false positives with condition no. 2, two of these railway sections (no. 17 and 61) are train stations and 
Author-produced version of the article published in Safety science, 2018; 110 part B : 253-267

442 they present low vulnerability according to the hydraulic diagnosis. They have large areas able to

443 store eventual water stagnation and are protected by large ditches. Railway sections no. 5, 19, and

44421 actually present very small catchment areas, of 8700,5400 and $4900 \mathrm{~m}^{2}$ respectively, and

445 according to the diagnosis, railway tracksides would be large enough to store and evacuate the quantity of water that could be generated by these small catchments. Railway section no. 42 presents a very high degree of exposure to surface runoff according to the IRIP method, but it has not been considered for works. This section has actually already been subject to particular modifications because of flooding problems. These modifications were undertaken in partnership with local regional organizations and the railway section has been equipped with a large aperture under the railway and a retention basin. So it can be considered that the section is effectively exposed to surface runoff but that it is sufficiently protected and thus less vulnerable. Railway section no. 25 was considered as less susceptible to landslide during the first field expertise, with observed traces of past shallow landslides maybe due to rabbit holes. But, this railway section has been retained for further analysis and thus was not selected for regeneration works. Finally, railway section no. 46 presents high susceptibility levels of surface runoff transfer according to IRIP but the hydraulic diagnosis does not mention particular exposure to surface runoff. It would be interesting to get more details thanks to a deeper field analysis.

459 This quantitative comparison between the IRIP maps and the diagnosis results makes it possible to show the global performance of the IRIP method to detect railway sections exposed to surface runoff. Results are promising but show there is a need to focus on specific sections to better understand the meaning of IRIP detection (or not) in view of local configuration, and to improve the correspondence between runoff hazard assessment and selection by experts of railway sections at risk. The analysis must be pursued with a qualitative comparison at the catchment scale in order to better assess the contribution of the IRIP maps to understanding the environment surrounding the railway. 


\subsubsection{Railway section no. 9}
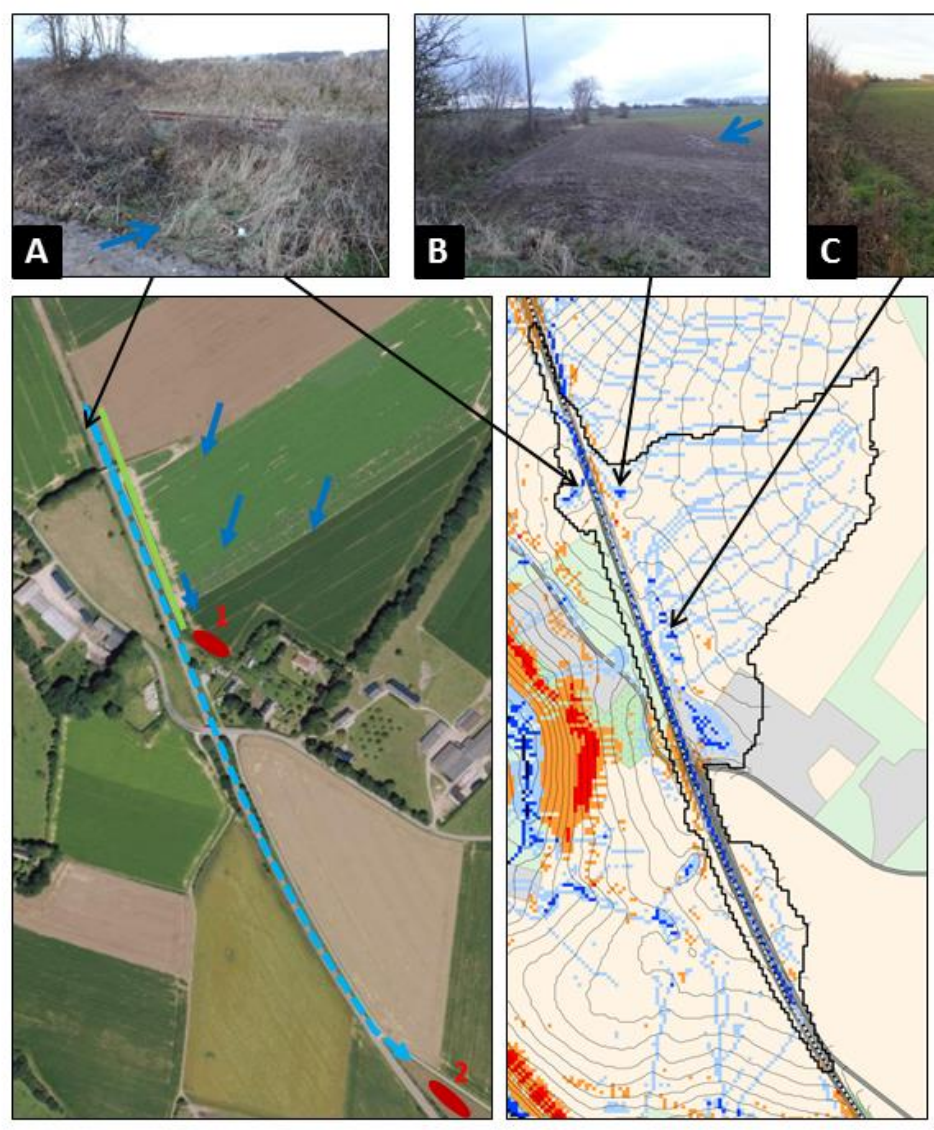

Legend:

$\square$ Catchment boundaries

DEM Contour lines at $1 \mathrm{~m}$

Accumulation susceptibility

$\square$ Medium (3)

- Strong (4)

- Very strong (5)

Transfer susceptibility

Medium (3)

- Strong (4)

- Very strong (5)

- Recommended Retention pond

- Buffer strips

$\rightarrow$ Flow direction

" Drainage

$0 \quad 50 \quad 100150200 \mathrm{~m}$

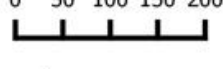

\section{个 $\mathbf{N}$}

Figure 6: Comparison of the IRIP susceptibility maps of surface runoff transfer of accumulation with the hydraulic diagnosis for railway section no. 9.

Figure 6 presents a 940 linear meter-long railway section, established in an excavation. The map on the left-hand side shows the measures recommended by hydraulic diagnosis. The dashed blue line represents the section which needs work, the dark blue arrows represents the directions of the preferential surface runoff paths observed in the field. The green line represents the location for the installation of a buffer strip, made with grass or hedges, to slow down surface runoff and to stop mud accumulating on the tracks. The two red spots show two solutions for installing a retention pond. The first location should retain surface runoff before reaching the tracks. The second location should receive surface runoff after having been drained along the track sides in order to avoid problems downstream. The map on the right-hand side shows the three highest levels of storm runoff transfer and accumulation susceptibility. The black line represents the catchment boundaries, that is, the area from which the railway section can potentially receive water from precipitation. 
Author-produced version of the article published in Safety science, 2018; 110 part B : 253-267

dark blue pixels, which is consistent with the choice of the section selected for works. High accumulation susceptibility can also be retrieved at the edge of the excavation which is consistent with the recommendation of installing a buffer strip and with the photos from the field, which show signs of moisture and mud deposits (photos B and C). One can also see a wider area of storm runoff accumulation at the location of the first solution for the retention pond, which let us state that it could be a better solution for protecting infrastructure than no. 2, which was designed for improving the situation downstream of the railway. The directions of the preferential paths for surface water identified on the field are retrieved on the IRIP maps with levels of accumulation of 3 and with far more details. Moreover, in the northern part of the railway section, on the left-hand side of the railway, a very small catchment is detected (photo A) with a high susceptibility to storm runoff accumulation. This susceptibility is confirmed by the photo $A$ and by the aerial photography which show mud deposits. At this point, the railway is established in a small embankment and is not equipped with any hydraulic system which makes the railway vulnerable to storm runoff. This point can be considered as at risk although the catchment is so small that significant water inflow is unlikely. Finally, the IRIP maps agree with the diagnosis and provide more information in the environment upstream of the railway. 
Legend:

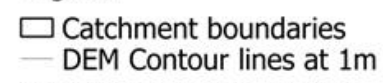
Accumulation susceptibility $\square$ Medium (3)

\section{- Strong (4)}

Transfer susceptibility

$\square$ Medium (3)

Strong (4)

- Very strong (5)

Existing

Retention pond

- Buffer strips

$\rightarrow$ Flow direction

" Drainage

$\begin{array}{lllll}0 & 50 & 100 & 150 & 200 \\ \mathrm{~m}\end{array}$
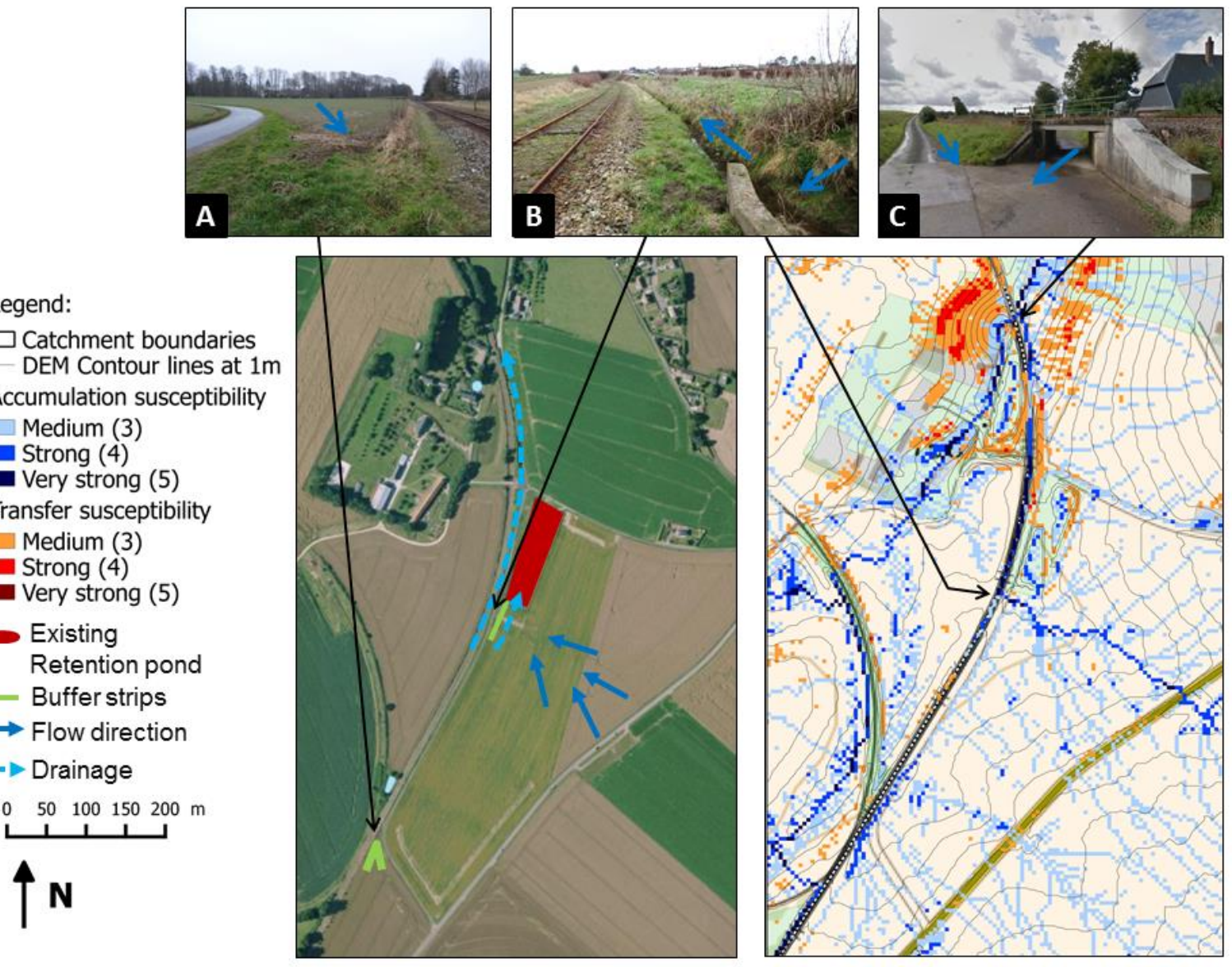

Figure 7: Comparison of the IRIP susceptibility maps of surface runoff transfer of accumulation with the hydraulic diagnosis for railway section no. 33.

Figure 7 presents another railway section of about 800 linear meters. The section is established at ground level in the southern part, in an excavation in the middle part, and on an embankment in the northern part. On the left-hand side map, two recommendations for installing buffer strips are indicated with the green lines and the red square indicates an already existing retention pond. On the right-hand side map, a main path of storm runoff arriving on the railway from the right hand side is detected by the IRIP map of accumulation susceptibility with levels of 4 and 5 , a part is flowing in the retention pond and another part is flowing in the drainage system along the railway (photo B) which is consistent with the flow direction observed on the field and the selected railway section for regeneration works. Regarding the significant size of the catchment intercepted by the railway (about $1.2 \mathrm{~km}^{2}$, too large to be displayed but computed on the map), the drainage system capacity might not be sufficient considering the potential storm runoff inflow. The regeneration works only consider drainage works explaining why no solution for installing a hydraulic structure crossing the railway has been proposed. However, building a crossing structure at the intersection with the main 
Author-produced version of the article published in Safety science, 2018; 110 part B : 253-267

519 surface runoff path could be interesting. According to the IRIP maps, the natural surface runoff path

520 is not to be intercepted by the railway and redirected toward the northern direction, but is to

521 continue on the other side of the railway and to connect with the important water flow path

522 downstream, indicated with high accumulation susceptibility levels. The question can be asked

523 whether the railway infrastructure manager is responsible for the management of the entire volume

524 of surface runoff coming from the upstream catchment or if it is responsible only for ensuring its

525 natural flow from upstream to downstream. Here, a risk of drainage ditches overflowing can be

526 expected. Such an incident could generate floods on tracks, erosion of the railway platform and

527 erosion of the embankment at the exit of the longitudinal drainage, near the higher levels of storm

528 runoff transfer (photo $\mathrm{C}$ ). At another location, on the southern part of the railway section, an

529 important surface water flow path is detected by the IRIP map: it corresponds to the

530 recommendation for a buffer strip (photo A) but no particular flow direction has been indicated.

531 Particular attention should be paid at this location which is exposed to surface runoff inflows. The

532 IRIP maps reveal the storm runoff spatial organization in the surroundings of the railway. Such

533 information can considerably support hydraulic experts in designing solutions to protect the railway

534 from storm water inflows. 


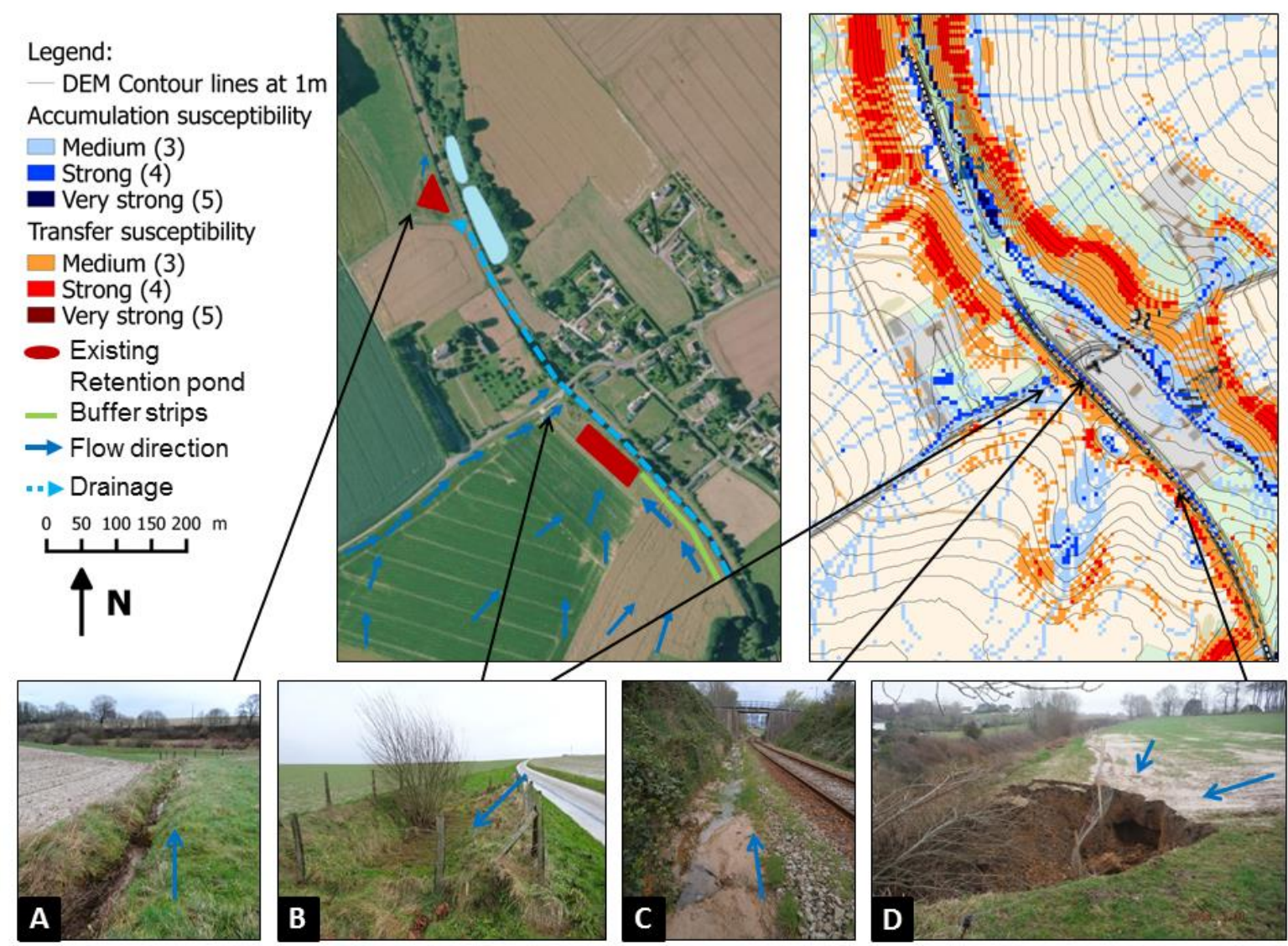

Figure 8: Comparison of the IRIP susceptibility maps of surface runoff transfer of accumulation with the hydraulic diagnosis for railway section no. 35 .

Figure 8 represents the third railway section. It is 1150 linear meters long and is established in an excavation. The catchment intercepted by this section is located in the left-hand side, with several storm runoff flow paths arriving perpendicularly to the railway. The important flow path, on the right-hand side, flows northward laterally to the railway but downstream. Anyway, the small town on the aerial photography and the downstream cities are frequently impacted by pluvial flooding. That is why two large retention ponds (light blue patches) can be seen on the northern part - they have been built by the agglomeration. Concerning the railway, the IRIP map presents strong accumulation susceptibility levels all along the section, meaning a high risk of track flooding (illustrated on photo C). Within the catchment, the flow directions indicated on the IRIP map agree with those observed in the field. Two already existing retention ponds belonging to the railway company protect the railway from storm runoff inflows. A small retention area has been set up to limit water coming from the road (photo B). However, on photo $D$, there were no protective structures and a landslide of the excavation occurred. This incident was due to a water stagnation area at the edge of the 
Author-produced version of the article published in Safety science, 2018; 110 part B : 253-267

embankment (mud deposits can be seen on the photo), which weakened the embankment, and a storm runoff inflow (small flow path upstream) on an area susceptible to runoff acceleration (orange and red pixels), which generated a landslide on the embankment slope. The deposit of materials on the tracks is a major risk of collision for a train, leading to a derailment risk. This location is recommended for installing a buffer strip which reflects this particular sensitivity. Along this railway section, this is the only location where the IRIP map indicates alternating patterns of high susceptibility to accumulation and transfer in the direct surrounding of the railway and where there is no protection. The other areas with high transfer susceptibility are farther away from the railway, or not directly linked with an important flow path. Finally, on this Figure, a lot of information is provided by the IRIP map, and an assessment of the local railway configuration is essential to identify locations at risk.

\subsection{IRIP maps interpretation guidelines}

The comparison between the hydraulic diagnosis results and the IRIP maps shows a good agreement of areas exposed to surface runoff and areas with recommended works inside and outside the railway right-of-way. This allows the extrapolation of some patterns of surface runoff spatial connectivity with the railway infrastructure. Here are four examples of configurations of hazards and vulnerability which lead to considering a railway section as being at risk. First, high accumulation levels located on rail tracks could mean a risk of flooding if the railway is established in an excavation. Secondly, high accumulation levels at the ridge of an excavation are a sign for potential surface water stagnation and could generate a risk of a landslide of the excavation slope by material saturation of water. Thirdly, high transfer susceptibility levels on the slope of an excavation could indicate a risk of landslide if the transfer area is related to a surface water flow path indicated in the accumulation map. Fourth, a surface water preferential path crossing a railway embankment transversally is a risk for embankment backfilling and destruction, so at those locations experts must ensure that an aperture exists within the embankment (for example a rail bridge as illustrated in Figure 7, photo C).

\subsection{Summary and limits of the comparison}

This study presents two degrees of evaluation of the IRIP method: a statistical analysis and a spatial analysis. The spatial analysis shows the agreement between the IRIP spatial information and the field observations. The statistical analysis shows that the IRIP method is an efficient tool to detect railway sections exposed to surface runoff for relatively long linear distances. For the quantitative analysis, two conditions have been tested for considering a section as exposed to surface runoff or not, one permissive condition and one more binding. Moreover, we attempted to take the structural vulnerability of the railway into account, considering that embankments with apertures under the railway are configurations with low vulnerability. Considering that apertures are indicators of surface 
Author-produced version of the article published in Safety science, 2018; 110 part B : 253-267

runoff occurrence, these configurations are changed from false positives to true positives. Finally, it makes POD varying from 94 to $100 \%$ and FAR from 20 to $26 \%$, along with extremely significant ChiSquare. However, we must recall some hypotheses that were made for this study and which must be taken into account in the interpretation of the results.

For this study, certain indicators and thresholds were adapted regarding the IRIP default parameterization, such as erodibility, slaking crust ability or the thresholds of slopes and topographic indexes. These changes are justified by a good knowledge of the local environment behavior acquired during previous studies and discussions with local actors. However, the hypotheses made as a result of IRIP method previous evaluations could be not applicable in the same way for other study areas. So additional tests must be performed to confirm the choices made for this study, or to find another parameterization which could better fit the comparison data, or else to analyze a possible change for other hydrological contexts. Concerning the repeatability of the results, input data are critical points. Indeed, good quality and high resolution data are important, but not available for all territories. Among the three input data required for the IRIP method, deciding which one is the most important in terms of quality depends on the objective of the study. For example, for territory planning or certain technical implementations regarding mitigation, the generation map will be relevant in order to know the poor infiltration capacity areas. Thus, quality of soil and land use data would be the most important. For an objective of impact assessment, the maps of transfer and accumulation would be the most relevant, so quality of the topographical data is the most important. Indeed, three indicators out of five are computed from topography for the map of transfer and four out of five for the map of accumulation. Figure 9 provides elements for discussing the required resolution of the topography. It shows two IRIP maps of the same part of the study area created with a 30-meter resolution DEM (left) and with a 5-meter resolution DEM (right). The map with the 30meter resolution shows the mains surface runoff preferential paths (blue), which are the main talwegs along with transfer areas (orange), which are located mainly on the steepest talweg sides. The map with the 5-meter resolution is the one used for the current study and shows so many details that it is difficult to distinguish them at this scale. Further details can be observed on the hillslopes with the accumulation map, and information about surface runoff transfer susceptibility is more localized. Finally, the spatial information of the two maps overlaps globally, but provides different types of information that should be used regarding the objective of the analysis. For example, an IRIP map with a high resolution can be used for local analysis, and a coarser resolution IRIP map could be used for very long railway stretches (above about $100 \mathrm{~km}$ of railway) with very large catchments, or to have a global understanding of the environment behavior. In general terms, the input data resolution should not be larger than the resolution of the physical phenomenon. 


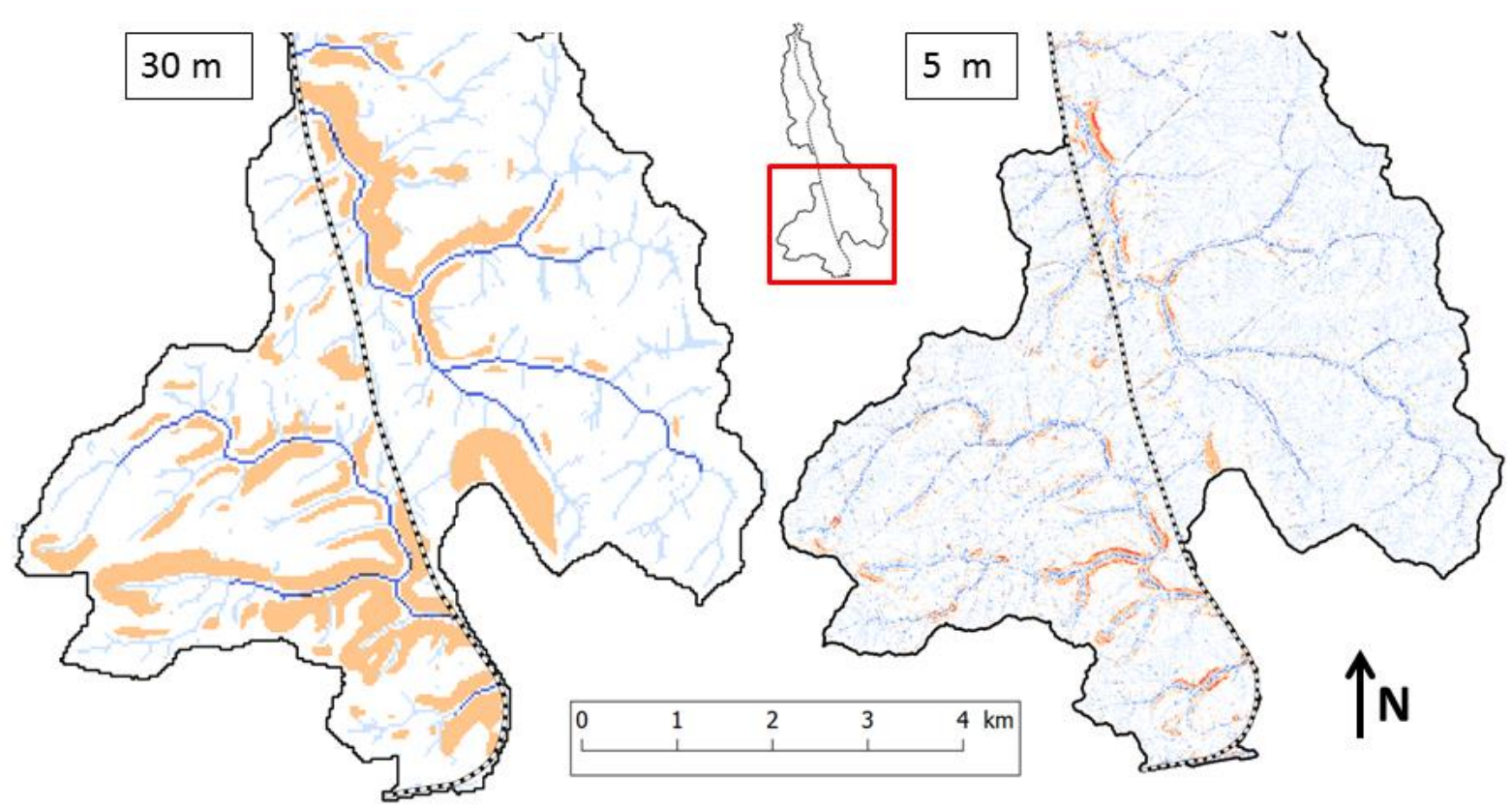

Figure 9: Surface runoff susceptibility maps created with the IRIP method on the same area using two different resolutions of digital elevation model: 30 meters (left) and 5 meters (right). Although the two maps overlap globally, different information can be obtained using different input data.

This study demonstrates the satisfying performance and the relevance of the IRIP method to perform hazard assessment. The IRIP maps can make a substantial contribution to identifying railway sections exposed to surface runoff and to better understanding the surrounding environment of the railway.

\section{Discussion}

The previous part presents interesting results about the correspondence between the surface runoff maps created with the IRIP method and the results of the hydraulic diagnosis, both with the quantitative and the qualitative comparison. Here, we discuss how the IRIP method can practically contribute to the current hydraulic risk assessment process. First, the current process is described, and then steps are identified where the IRIP method can directly contribute and where there is an opportunity to push forward the current methods. 

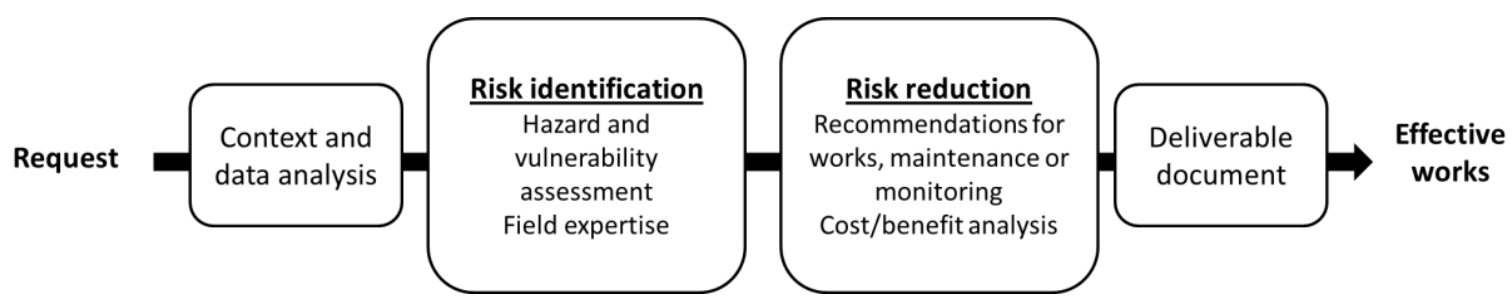

Figure 10: General scheme of the risk assessment process to manage hydraulic risks on the railway infrastructure

Risk assessments are performed on railway sections or on railway network parts and aim at optimizing the maintenance strategy in terms of works, maintenance, and monitoring regarding specific risks. Figure 10 presents the general risk assessment process. It starts with a risk assessment request from the infrastructure manager to the engineering services. Experts then collect and gather all information about the study area. Information can be contextual about the current request, the stakeholders, and the final objectives. It can be about the infrastructure configuration and its elements, and it can be about past studies or past disorders on the study area, within the railway right-of-way and within the surrounding environment. Then it follows two main steps, the risk identification and the risk reduction. The risk identification step aims at assessing the hazard to which the railway is exposed, its intensity, and its probability of occurrence. It also aims at assessing the infrastructure structural vulnerability, in order to define railway sections at risk. Field assessments and discussions with local actors help the experts with the hazard and vulnerability assessment. Risk ranking can be made along the study area in order to prioritize sections at risk. Then the risk reduction step aims at making recommendations in terms of works, maintenance, and monitoring, providing technical solutions and also hierarchizing actions. For this step, compromises are found between costs, efficiency, and feasibility. Discussions with the infrastructure manager also allow analyzing the risk acceptability and the conditions of this acceptability. Finally, a deliverable document is provided to the infrastructure manager and effective works can start. This process remains general and each risk assessment has specific objectives and constraints that must be taken into account for each step of the process. Examples of contributions of the IRIP method are suggested for each step.

\subsection{Contribution to context and data analysis} At the start of a risk assessment, experts must dedicate time to gathering data about the study area. Implicitly, a wealth of knowledge is provided by local actors and company employees that are used to working on the study area and that know areas susceptible to specific risks. Difficulties lie in the fact 
Author-produced version of the article published in Safety science, 2018; 110 part B : 253-267

that soft knowledge remains subjective and that can be lost or modified with long periods of time. Knowledge can also be lost when employees move or retire. Concerning more conventional data, archive data are generally difficult to use (Saint-Marc et al., 2016). Storage locations can be difficult to access, storage conditions are often not perennial, and the information is difficult to extract regarding the quantity of documents. Using numerical databases can also be difficult due to the large number of available databases, which have different operational objectives and which focus on different elements of the infrastructure. Regarding the quantity of data, information is often difficult to process. So information about a study area can be difficult to gather and especially when analyzing the surface runoff hazard, since there is no hazard mapping available on the railway network scale. For this step, the IRIP method can provide a reference map of surface runoff susceptibility along railways. The IRIP maps can be used as the basis when starting an assessment, to better assess the behavior of the environment surrounding the railway. Moreover, the IRIP method uses GIS (Geographical Information System) software, so the IRIP maps can be combined with all other information available on the study area (railway infrastructure, impact locations, surrounding structures) and information can be displayed on the same map. Although additional assessment is needed to interpret the data, gathering the data in a single visual tool can facilitate its processing (Saint-Marc et al., 2014). Further dialog between experts and project sponsors would also be useful in this step. Once the area characteristics have been analyzed, the needs can be detailed and objectives can be refined.

\subsection{Contribution to risk identification}

This study shows that the surface runoff susceptibility maps created with the IRIP method can bring valuable information for hazard assessment. The IRIP method can bring direct contribution in terms of accuracy and time saving. The IRIP method brings accuracy on the qualification of surface runoffrelated risks. Indeed, the three maps of generation, transfer, and accumulation bring information on the forms that surface runoff can get. Erosion or landslide can be expected for high transfer susceptibility areas. Floods or mud deposits can be expected for high accumulation susceptibility areas. Further assessment about the vulnerability of the railway infrastructure makes it possible to anticipate particular types of impact. More generally, the IRIP method is an additional tool to support decision-making. Experts can rely on the maps to confirm their analysis or to explain it. Moreover, the IRIP method can save time for the field assessment. The maps can help with the preparation of the field works and by supporting field observations. Indeed, the IRIP maps can help deciding which sites to visit by prioritizing the sites with the highest susceptibility levels. Moreover, the IRIP maps are a simple combination of landscape factors, so they help the expert to interpret landscape features such as the catchment boundaries, the surface water preferential path, areas with low 
Author-produced version of the article published in Safety science, 2018; 110 part B : 253-267

infiltration capacities, etc. Moreover, the three maps of storm runoff generation, transfer, and accumulation can orient the expert on the field by knowing what is expected to be seen and where. For example, areas susceptible to storm runoff transfer will present erosion traces and areas susceptible to storm runoff accumulation will present humidity, water stagnation or sediment mud deposits. More and more, experts have access to digital tools during their field assessments, so they can carry tools with GIS software which collate all the information about the study area. A potential evolution of the IRIP method could be the automatic detection of accumulation and transfer patterns near particular railway configurations, as identified in the map interpretation guidelines.

\subsection{Opportunity to push forward the risk reduction methods} Recommendations of solutions in terms of works, maintenance or monitoring can sometimes require creativity in order to optimize the effects, minimize costs, and provide sustainable solutions. In some cases, for surface runoff issues, standard hydraulic structures and drainage systems are not sufficient, since surface runoff not only carries water but also mud and debris that can clog structures and significantly reduce their capacity. Moreover, in some areas, surface runoff impacts are recent because of changes in the upstream environment (i.e. urbanization, forest turning into cultivated land). In some cases, there is no space available for adapting the railway with new structures. It is also worth considering who is responsible for the management of this new influx of pluvial water. These cases illustrate the fact that it is sometimes necessary to manage water issues outside the railway right-of-way, at the origin of the problem. These are not usual methods because it is complex to communicate with the other stakeholders. They can have the same surface runoff issues but not the same constraints and it can be difficult to work outside the railway right-of-way from a legal point of view. The current processes will have to evolve in this direction. The IRIP maps provide information about the spatial catchment characteristics and its surface runoff exposure. The maps can help adapting the mitigation techniques depending on the area. For high generation susceptibility areas, water infiltration capacity must be improved, for example with retention basins. The maps can help to choose the location of the basins. For areas with high transfer susceptibility (soil loss issues), it can be suggested to plant vegetation in order to stabilize earth and limit soil losses. For areas with high accumulation susceptibility, it can be suggested to implement wetlands (Fressignac et al., 2016) and to minimize vulnerability.

Moreover, the IRIP maps, being visual tools, can facilitate the communication between the project stakeholders. When convincing others about the importance of a recommendation, presenting model outputs which support this analysis and the conclusions can be helpful. There is a need for educational tools to support discussions with local actors and with project sponsors who are often not accustomed to implementing alternative techniques outside the railway right-of-way. The expert 
Author-produced version of the article published in Safety science, 2018; 110 part B : 253-267

must be able to explain the behavior of the catchment and the contribution of the different areas to prove the necessity of implementing such solutions for managing storm runoff-related risks.

\section{Conclusion}

This study presents interesting results when comparing the surface runoff maps created with the IRIP method and the result of a hydraulic diagnosis. The quantitative comparison shows high probabilities of detection along with low false alarm ratios. The qualitative comparison shows good correspondence between the IRIP maps and the field observations. This indicates a good performance and high level of reliability of the IRIP method to detect railway sections exposed to surface runoff. These results suggest that the IRIP method could help performing risk assessment studies. Similar results were obtained for another railway line, a $80 \mathrm{~km}$ railway stretch from Rouen to Le Havre (Normandie county) (Lagadec, 2017). The discussion part shows that the IRIP method can make a direct contribution to numerous tasks in the risk analysis process and suggests some examples for applications. Moreover, having a better understanding of the surface runoff hazard opens up new opportunities to push forward the risk reduction method, particularly by managing surface runoff issues at the origins of the problems, outside the railway right-of-way. Integrating the IRIP method into the current process and more generally, integrating a new tool into current working processes can be challenging. However, the innovation part, between the research and the development process, is essential for achieving a real improvement, which in our case would be a sustainable development of the railway network in its environment.

Acknowledgments:

We would like to thank Loïc Raigondeau, SNCF hydraulic specialist and Bréauté-Fécamp hydraulic diagnosis supervisor, for his support throughout this work and his valuable advice. We would also like to thank other contributors to the Bréauté-Fécamp risk analysis, especially Yoni Poitevin and Ahlem Hasnaoui. More generally speaking, we thank all the IRIP project contributors, especially Judicaël Dehotin, a key proponent of the development of the IRIP method. Finally, we thank ANRT (Agence Nationale de la Recherche et de la Technologie) for its partial funding of this work. 
Amblard, J., Capoccioni, C.P., Nivon, D., Mellal, L., De Cesare, G., Ghilardi, T., Jafarnejad, M., Battisacco, E., 2015. Analysis of Ballast Transport in the Event of Overflowing of the Drainage System on High Speed Lines. International Journal of Railway Technology 4, 19-43. doi:10.4203/ijrt.4.2.2

Ballabio, C., Panagos, P., Monatanarella, L., 2016. Mapping topsoil physical properties at European scale using the LUCAS database. Geoderma 261, 110-123. doi:10.1016/j.geoderma.2015.07.006

Beven, K.J., 2011. Rainfall-runoff modelling: the primer. John Wiley \& Sons.

Beven, K.J., Kirkby, M.J., 1979. A physically based, variable contributing area model of basin hydrology / Un modèle à base physique de zone d'appel variable de l'hydrologie du bassin versant. Hydrological Sciences Journal 24, 43-69. doi:10.1080/02626667909491834

Cerdan, O., Le Bissonnais, Y., Souchère, V., King, C., Antoni, V., Surdyk, N., Dubus, I., Arrouays, D., Desprats, J.-F., 2006. Guide méthodologique pour un zonage départementale de l'érosion des sols Rapport no. 3 : Synthèse et recommandations générales (No. BRGM-RP-55104-FR). BRGM - INRA.

Cerdan, O., Souchere, V., Lecomte, V., Couturier, A., Le Bissonnais, Y., 2002. Incorporating soil surface crusting processes in an expert-based runoff model: Sealing and Transfer by Runoff and Erosion related to Agricultural Management. Catena 46, 189-205. doi:10.1016/S03418162(01)00166-7

Chazelle, B., Lambert, L., Capoccioni, C.P., 2014. Railway vulnerability in case of extremes floods. Knowledge and risk management. La Houille Blanche 48-54. doi:10.1051//hb/2014016

Dabney, S.M., Yoder, D.C., Vieira, D.A.N., Bingner, R.L., 2011. Enhancing RUSLE to include runoffdriven phenomena. Hydrological Processes 25, 1373-1390. doi:10.1002/hyp.7897

Defrance, D., Javelle, P., Organde, D., Ecrepont, S., Andréassian, V., Arnaud, P., 2014. Using damage reports to assess different versions of a hydrological early warning system. Hydrology and Earth System Sciences Discussions 11, 4365-4401. doi:10.5194/hessd-11-4365-2014

Dehotin, J., Breil, P., 2011a. Technical report of the IRIP project: mapping the flooding by runoff (Technical report). IRSTEA Hydrology-Hydraulic Research Unit.

Dehotin, J., Breil, P., 2011b. IRIP project: Research bibliographic report on surface runoff mapping (Literature review). IRSTEA Hydrology-Hydraulic Research Unit.

Dehotin, J., Breil, P., Braud, I., de Lavenne, A., Lagouy, M., Sarrazin, B., 2015a. Detecting surface runoff location in a small catchment using distributed and simple observation method. Journal of Hydrology 525, 113-129. doi:10.1016/j.jhydrol.2015.02.051

Dehotin, J., Chazelle, B., Laverne, G., Hasnaoui, A., Lambert, L., Breil, P., Braud, I., 2015b. Applying runoff mapping method IRIP for flooding risk analysis on railway infrastructure. La Houille Blanche 56-64. doi:10.1051/lhb/20150069

Fressignac, C., Breil, P., Matillon, Y., Nullans, A., Chazelle, B., Sarrazin, B., Vallod, D., 2016. Assurer la maitrise du ruissellement grâce aux zones humides au voisinage des infrastructures de transport dans une perspective de conservation de la biodiversité. VertigO-la revue électronique en sciences de l'environnement. doi : 10.4000/vertigo.17406

Hatchuel, A., Le Masson, P., Weil, B., 2001. From R\&D to RID: Design strategies and the management of innovation fields, in: 8th International Product Development Management Conference. pp. 415-430.

Hogan, R.J., Mason, I.B., 2012. Deterministic forecasts of binary events. Forecast Verification: A Practitioner's Guide in Atmospheric Science, Second Edition 31-59. doi:10.1002/9781119960003.ch3

Javelle, P., Demargne, J., Defrance, D., Pansu, J., Arnaud, P., 2014. Evaluating flash-flood warnings at ungauged locations using post-event surveys: a case study with the AIGA warning system. Hydrological Sciences Journal 59, 1390-1402. doi:10.1080/02626667.2014.923970 
Author-produced version of the article published in Safety science, 2018; 110 part B : 253-267

The original publication is available at https://www.sciencedirect.com/science/article/pii/S0925753517309372 doi : 10.1016/j.ssci.2018.05.014

Klasing-Chen, M., Le Masson, P., Weil, B., Laousse, D., Aknin, P., Lagadec, L.-R., Submitted. How can we create mutually beneficial industry-university collaborations? Identifying a gap in collaborations design. Presented at the 21st International Conference on Engineering Design, University of British Columbia, Vancouver, Canada.

Lagadec, L.-R., Breil, P., Chazelle, B., Braud, I., Moulin, L., 2016a. Use of post-event surveys of impacts on railways for the evaluation of the IRIP method for surface runoff susceptibility mapping. Presented at the FloodRisk, Lyon, France. doi: 10.1051/e3sconf/20160710005

Lagadec, L.-R., Patrice, P., Chazelle, B., Braud, I., Dehotin, J., Hauchard, E., Breil, P., 2016b. Description and evaluation of an intense surface runoff susceptibility mapping method. Journal of Hydrology 541, 495-509. doi: 10.1016/j.jhydrol.2016.05.049

Lagadec, L.-R., 2017. Evaluation and development of the IRIP method for intense pluvial runoff mapping. Application to the railway context. Doctoral thesis. Grenoble Alpes University Community.

Le Bissonnais, Y., Cerdan, O., Lecomte, V., Benkhadra, H., Souchere, V., Martin, P., 2005. Variability of soil surface characteristics influencing runoff and interrill erosion. Catena 62, 111-124. doi:10.1016/j.catena.2005.05.001

Le Gouee, P., Delahaye, D., Bermond, M., Marie, M., Douvinet, J., Viel, V., 2010. SCALES: a large-scale assessment model of soil erosion hazard in Basse-Normandie (northern-western France). Earth Surface Processes and Landforms 35, 887-901. doi:10.1002/esp.1942

Maurer, H., Rudzikaite, L., Kiel, J., Partzsch, I., Pelikan, V., Sedlacek, N., Mitsakis, E., Stamos, I., Papanikolaou, A., Celano, M., 2012. Weather Extremes: Assessment of Impacts on Transport Systems and Hazards for European Regions. Weather project synthesis report. doi:<hal00803668>

Naulin, J.-P., Payrastre, O., Gaume, E., 2013. Spatially distributed flood forecasting in flash flood prone areas: Application to road network supervision in Southern France. Journal of Hydrology 486, 88-99. doi:10.1016/j.jhydrol.2013.01.044

Pons, F., Delgado, J.-L., Guero, P., Berthier, E., 2010. EXZECO: a gis and dem based method for predetermination of flood risk related to direct runoff and flash floods. Presented at the 9 th International Conference on Hydroinformatics, Tianjin, CHINA.

Rubin, J., 1967. Optimal classification into groups: An approach for solving the taxonomy problem. Journal of Theoretical Biology 15, 103-144. doi:10.1016/0022-5193(67)90046-X

Saint-Marc, C., Capoccioni, C.P., Anne, R., Chenier, D., 2016. L'étude des inondations historiques majeures et leurs impacts. Revue Générale des Chemins de Fer 263.

Saint-Marc, C., Chenier, D., Coeur, D., Capoccioni, C.P., Davoine, P.-A., Villanova-Oliver, M., 2014. Apprendre du passé pour optimiser la prévention et la gestion des inondations sur le ferroviaire, in: Symposium International GEORAIL 2014. doi: hal-01383491

Sivapalan, M., Beven, K., Wood, E.F., 1987. On hydrologic similarity: 2. A scaled model of storm runoff production. Water Resources Research 23, 2266-2278. doi: 10.1029/WR023i012p02266

Smith, R.E., Goodrich, D.C., Woolhiser, D.A., Unkrich, C.L., 1995. KINEROS-A kinematic runoff and erosion model. Computer models of watershed hydrology. 20, 627-668.

Stanski, H.R., Wilson, L.J., Burrows, W.R., 1989. Survey of common verification methods in meteorology. World Meteorological Organization Geneva.

Thompson, D.B., 2007. The rational method. RO Anderson Engineering.

Versini, P.-A., Gaume, E., Andrieu, H., 2010. Assessment of the susceptibility of roads to flooding based on geographical information - test in a flash flood prone area (the Gard region, France). Natural Hazards and Earth System Sciences 10, 793-803. doi:/10/793/2010/ 